\title{
Gestión del cambio: una propuesta metodológica desde el proceso estratégico*
}

\author{
Regina Soriano - Rivera \\ Pontificia Universidad Católica del Perú \\ rsoriano@pucp.edu.pe
}

A partir de una revisión bibliográfica, se describirán los conceptos y enfoques planteados por diversos autores, los mismos que permitirán acercarse a la comprensión de este complejo tema que implica muchos retos organizacionales desde un punto de vista sistémico. El artículo se iniciará con el análisis de dos enfoques centrales que se persiguen en la gestión: el pensamiento sistémico y la generación de valor. Enseguida, se definirá el concepto de proceso estratégico para luego abordar la gestión del cambio, los tipos de cambio, sus elementos y algunos modelos propuestos por otros autores. Finalmente, se ofrecerá un marco metodológico o modelo de gestión del cambio que pretende servir de guía o parámetro general susceptible de ser implementado, que sea lo suficientemente integrador y al mismo tiempo flexible, capaz de ser adaptado a la complejidad particular de cualquier organización.

Palabras clave: gestión del cambio; modelo de cambio; pensamiento sistémico; generación de valor; proceso estratégico

Change Management: a Methodological Proposal from the Strategic Process

Starting with a literature review, the description of concepts and approaches raised by different authors will be exposed, concepts which in turn will allow the reader to gain some understanding of this complex theme that implies many organizational challenges from a systemic point of view. The first issue to be addressed is the analysis of two main approaches that are sought in management: systemic thinking and generation of value. Then, the concept of strategic process will be defined so as to later address change management, types of change, its elements and some models proposed by other authors. Finally, a methodological framework or change management, model will be presented as a guide or general parameter prone to being implemented, it being sufficiently inclusive but at the same time flexible, so that it can be adapted to the particular complexity of any organization.

Key words: change management; change model; systemic thinking; generation of value; strategic process

\footnotetext{
"La autora resalta y agradece el aporte de Víctor Yockteng, quien se desempeñó como su director de consultoría y le transmitió sus conocimientos y experiencia en Gestión del Cambio, los mismos que han sido recogidos para plantear el modelo materia de este artículo; así como a Aída Velez, Gerente Nacional de Gestión Humana de Olímpica S.A., por la autorización del uso de la información de la Gestión del Cambio implementada en el Proyecto Gacela que se presenta en el Caso de Aplicación.
} 


\section{Antecedentes y objetivo}

Diversos autores abordan el tema de la gestión del cambio como una herramienta facilitadora del tránsito de la formulación a la implementación estratégica (Daft 2011; David 2013; Johnson, Scholes y Whittington 2006). Algunos lo abordan de manera superficial; otros, con profundidad (Duck 2000; Kotter 2000). Algunos definen los tipos de cambios (Daft 2011; Quinn y Voyer 1997; Tushman, Newman y Romanelli 1997), su necesidad (Taylor y Morgan 2014), los enfoques de abordajes (Barroso Rodríguez y Delgado Fernández, 2007; Sandoval 2014), las competencias que se requieren (Society for Humman Resource Management 2007), sus elementos (Blázquez Manzano 2013), los factores que influyen en él o su envergadura. Otros plantean recomendaciones para el cambio exitoso (Ferrazzi 2014; Gettler 2015), señalan los errores que se cometen en el proceso (Aiken y Keller 2009) o por qué la gestión del cambio debería cambiar (Ashkenas 2013), etc. Sin embargo, el lector podría quedarse con algunas dudas respecto a cómo ejecutar la gestión del cambio de manera apropiada y práctica en su organización (Ashkenas 2013).

En ese sentido, el objetivo de este artículo es plantear una propuesta metodológica de la gestión del cambio susceptible de ser implementada desde el proceso estratégico y que permita potenciar el éxito de los procesos de cambio organizacional, desde una perspectiva sistémica y generadora de valor.

\section{2. ¿Para quién y con qué perspectivas?}

Para iniciar, es preciso definir quiénes pueden aplicar la gestión del cambio. Si se tiene en cuenta que "las organizaciones son 1) entidades sociales que 2) están dirigidas a las metas, 3) están diseñadas como sistemas de actividades estructuradas y coordinadas en forma deliberada y 4) están vinculadas al entorno" (Daft 2011: 11), entonces jtodas las organizaciones pueden aplicarla! Las organizaciones multinacionales, las pequeñas empresas familiares, las organizaciones sin fines de lucro y las gubernamentales pueden ser susceptibles de pasar por procesos de cambio, por su naturaleza humana (es decir, dado su carácter social), y, por ende, dichos procesos deben ser gestionados apropiadamente. Claro está que la forma de aplicarla será diferente en cada una, dependiendo de sus características únicas.

Respecto a la perspectiva sistémica, es importante señalar que su incorporación en este artículo es crucial dada la necesidad de contar con la visión holística que todo gestor debe tener. "Los negocios y otras empresas humanas también son sistemas. También están ligados por tramas invisibles de actos interrelacionados, que a menudo tardan años en exhibir plenamente sus efectos mutuos" (Senge 2005: 15). Esta es la primera característica de una organización inteligente y es primordial, ya que:

Como nosotros mismos formamos parte de esa urdimbre, es doblemente difícil ver todo el patrón de cambio. Por el contrario, solemos concentrarnos en fotos instantáneas, en partes aisladas del sistema, y nos preguntamos por qué nuestros problemas más profundos nunca se resuelven. El pensamiento sistémico es un marco conceptual, un cuerpo de conocimientos y herramientas que se ha desarrollado en los últimos cincuenta años, para que los patrones totales resulten más claros, y para ayudarnos a modificarlos (Senge 2005: 15-16). 
El pensamiento sistémico es integrador, holístico y completo; permite la visualización de una panorámica que ayuda a comprender que todos los elementos organizacionales (internos y externos) son o pueden ser susceptibles de ser impactados por cualquier decisión y/o acción. Esta perspectiva es fundamental que todo gestor la tenga presente en todo momento, ya que todas las situaciones son capaces de ser analizadas bajo esta ideología; en particular, es importante aplicarla en una situación de cambio.

Otro concepto importante de ser abordado previamente al tema central de la gestión del cambio es la generación de valor. El valor de una empresa usualmente se calcula en términos financieros. "Virtualmente, todos los individuos y organizaciones ganan u obtienen dinero y lo gastan o lo invierten. Las finanzas están relacionadas con este proceso, las instituciones, los mercados y los instrumentos implicados en la transferencia de dinero entre individuos, empresas y gobiernos" (Gitman 2003: 3). Tradicionalmente, se puede decir que su valor es la capacidad de generar una rentabilidad: "Los accionistas esperan ganar un rendimiento recibiendo dividendos -distribuciones periódicas de utilidades- o realizando ganancias mediante incrementos en el precio de las acciones" (Gitman 2003: 5).

Sin embargo, para algunos autores, las organizaciones generan valor cuando atienden satisfactoriamente a todos sus stakeholders (internos: accionistas, directivos y trabajadores; y externos: clientes, proveedores, el gobierno, las comunidades cercanas y la sociedad en general). Según Porter y Kramer, el análisis estratégico debe incluir a todas las fuerzas que intervienen en su modelo de negocio. Este debe ser capaz de "crear el valor compartido y no sólo ganancias per se" (2011: 4). Traduciendo su propuesta, estos autores plantean que "las empresas deben tomar el liderazgo para crear negocios y sociedad juntos nuevamente" (2011: 4). Este concepto de valor compartido se enfoca en la "conexión entre el progreso económico y social que desata el crecimiento global de una compañía" (2011: 5). Las empresas pueden generar espacios para desarrollar valor compartido cuando "recrean productos y mercados, redefinen su productividad en la cadena de valor permitiendo el desarrollo local de clusters" (2011: 5).

Por otro lado, Hamel sostiene que el valor se consigue con la innovación estratégica:

La cuestión parece indudable: en un mundo discontinuo, la innovación estratégica es la clave de la creación de riqueza. La innovación estratégica es la capacidad de reconcebir el modelo actual de negocio de forma que cree un nuevo valor para los clientes, deje fuera de juego a los competidores y produzca nueva riqueza para todos los participantes en la empresa. La innovación estratégica es el único camino hacia el éxito para los nuevos operadores, dada su enorme desventaja de recursos, y la única vía para que las empresas consolidadas renueven su apuesta por el éxito. Si redefinimos la medida del éxito empresarial como la participación en la nueva creación de riqueza en el marco de un ámbito genérico de oportunidades (por ejemplo, la energía, el transporte, las comunicaciones, la informática, etc.), la innovación se convierte en un imperativo irrenunciable (2006: 19).

La gestión de la innovación está muy vinculada con la gestión del cambio, ya que, de acuerdo a cómo se innove en la organización (de manera radical o incremental), se podrán plantear estrategias de gestión del cambio que sean más acordes. “El potencial 
que tiene una organización para innovar, es decir la habilidad para adoptar o implementar con éxito mejoras graduales o productos nuevos puede diferir sustancialmente de una organización a otra" (Rueda-Cáceres y Sánchez-Torres 2015: 1). Los factores que apoyan la capacidad de innovación organizacional son cinco facilitadores de gestión: cultura, estrategia, estructura organizacional, asignación de recursos y gestión de conocimiento; estos favorecen la transformación continua de conocimiento (Rueda-Cáceres y Sánchez-Torres 2015: 1). La cultura se considera como un elemento primordial que será la columna vertebral de los otros facilitadores de gestión (Rueda-Cáceres y Sánchez-Torres 2015: 1). Por otro lado, el vínculo entre la estrategia y la estructura organizacional es vital como motor de la gestión de la innovación:

Dado que las empresas crecen, hay una tendencia a añadir capas, cada vez más mecanicistas y de burocracia institucionalizada (Kanter, 1983). Las empresas de alto rendimiento permiten y motivan el comportamiento innovador creando fronteras de negocio permeables ayudando a romper las barreras que separan las funciones, los grupos de productos y los negocios (Ashkenas, 1998; Maira \&Thomas, 1998). Cuanto más permeable y orgánica la estructura, mayor será la posibilidad de que las ideas innovadoras surjan (Crossan \& Apaydin, 2010) (citado en Rueda-Cáceres y Sánchez-Torres 2015: 4).

Es decir, las organizaciones orgánicas son las que favorecen la innovación más que las mecánicas. Las principales dimensiones estructurales de una organización orgánica se caracterizan por presentar un “bajo grado de formalización en términos de especificación de las obligaciones del trabajo y escasa división de actividades a realizar, pocas reglas, comunicación lateral significativa y descentralización en la toma de decisiones" (Claver Cortés, Pertusa Ortega y Molina Azorín 2006: 188); es decir, baja formalización, baja complejidad (poca diferenciación horizontal, vertical o espacial) y baja centralización: estas características hacen más flexible este tipo de organización (Claver Cortés y otros 2006: 190). Por lo tanto, las organizaciones orgánicas generarían más valor.

Por otro lado, otros autores destacan que la generación de valor se logra a través de las ventajas competitivas. Y estas se consiguen cuando la organización aprende:

Como decía recientemente la revista Fortune: "Olvide sus viejas y trilladas ideas acerca del liderazgo. La empresa de mayor éxito de la década del 90 será algo llamado organización inteligente". Y Arie de Geus, jefe de planificación de Royal Dutch/Shell, ha declarado: "La capacidad de aprender con mayor rapidez que los competidores quizá sea la única ventaja competitiva sostenible". Al crecer la interconexión en el mundo y la complejidad y el dinamismo en los negocios, el trabajo se vincula cada vez más con el aprendizaje (Senge 2005: 11).

Una definición ampliamente aceptada de ventaja competitiva es la de Michael Porter, quien afirma que es el "valor que una empresa logra crear para sus clientes", la cual requiere de algunas herramientas para crearla y mantenerla, como la cadena de valor (permite a los directivos aislar las fuentes de valor que marcan el precio más competitivo, 
y los criterios para sustituir un producto o servicio por otro) y las cinco fuerzas competitivas (proporcionan un análisis completo de la competitividad en una determinada industria) (Porter 2010). Las fuerzas competitivas revelan las causas de la competencia en la industria, por lo que un estratega que entiende este fenómeno puede detectar las amenazas y oportunidades que se le presentarán en el entorno competitivo y estar mejor preparado para enfrentarlas (Porter 2008: 93).

Otra definición relacionada con la anterior es la de la hipercompetitividad. "Actualmente estamos en un ambiente hipercompetitivo que origina que los entornos sean altamente cambiantes, dinámicos, complejos e impredecibles" (Lloréns Montes, Verdú Jover y García Morales 2006: 393). Para obtener y sostener ventajas competitivas en estas situaciones, se debe tener la habilidad para generar nuevas ventajas, es decir, la capacidad de aprender continua y rápidamente para aprovechar las oportunidades del mercado (LLoréns Montes y otros 2006: 393).

Estos conceptos preliminares son importantes debido a que deben ser una guía para cualquier iniciativa de cambio: la gestión del cambio puede aplicarse a cualquier tipo de organización, el pensamiento sistémico debe predominar en el diseño de las estrategias de gestión del cambio y la generación de valor compartido debe pretenderse como fin último; se genera valor cuando las organizaciones se orientan hacia lo orgánico, innovan y son capaces de sostener y generar nuevas estrategias en escenarios turbulentos.

\section{El proceso estratégico}

El proceso estratégico (D'Alessio Ipinza 2013: 10) ha sido tratado por diversos autores en los últimos años. Algunos lo conocen como dirección estratégica (Johnson y otros 2006), administración estratégica (David 2013: 5), proceso administrativo (Robbins y De Cenzo 2002: 6) o, incluso, liderazgo estratégico (Hill, Jones y Schilling 2015: 4). Cada uno tiene diferentes particularidades, componentes y términos; y claro, se evidencian elementos comunes.

Por ejemplo, la mayor parte de autores identifican con claridad la formulación y la implementación procurando darle una temporalidad en una serie de etapas más o menos definidas (Mintzberg, Quinn y Voyer 1997: xxi). Esto también lo evidencia Jhonson; sin embargo, define el concepto que engloba estas etapas como dirección estratégica: "La dirección estratégica incluye la comprensión de la posición estratégica de una organización, las elecciones estratégicas para el futuro y la conversión de la estrategia en acción" (Johnson y otros 2006: 16). Para D'Alessio, el proceso estratégico tiene cuatro etapas; la última incluye conclusiones y recomendaciones:

(a) formulación, que es la etapa de planeamiento propiamente dicha, en la que se procurará encontrar las estrategias que llevarán a la organización de la situación actual a la situación futura deseada; (b) implementación, en la cual se ejecutarán las estrategias retenidas en la primera etapa, es la etapa más complicada por lo rigurosa que es; y (c) evaluación y control, cuyas actividades se efectuarán de manera permanente durante todo el proceso para monitorear las etapas secuenciales [...]; aparte de estas tres etapas existe una etapa final, que presenta las conclusiones y recomendaciones finales. Cabe resaltar que el proceso estratégico 
se caracteriza por ser interactivo, pues participan muchas personas en él, e iterativo, en tanto genera una retroalimentación repetitiva (D’Alessio Ipinza 2013: 10).

Adicionalmente, D'Alessio considera las cinco actividades administrativas (planificar, organizar, dirigir, coordinar y controlar) descritas por Henry Fayol al inicio del siglo XX (citado en Robbins y De Cenzo 2002: 6) en las etapas del proceso estratégico. Esto puede verse en la siguiente figura:

Figura 1: Etapas del proceso estratégico

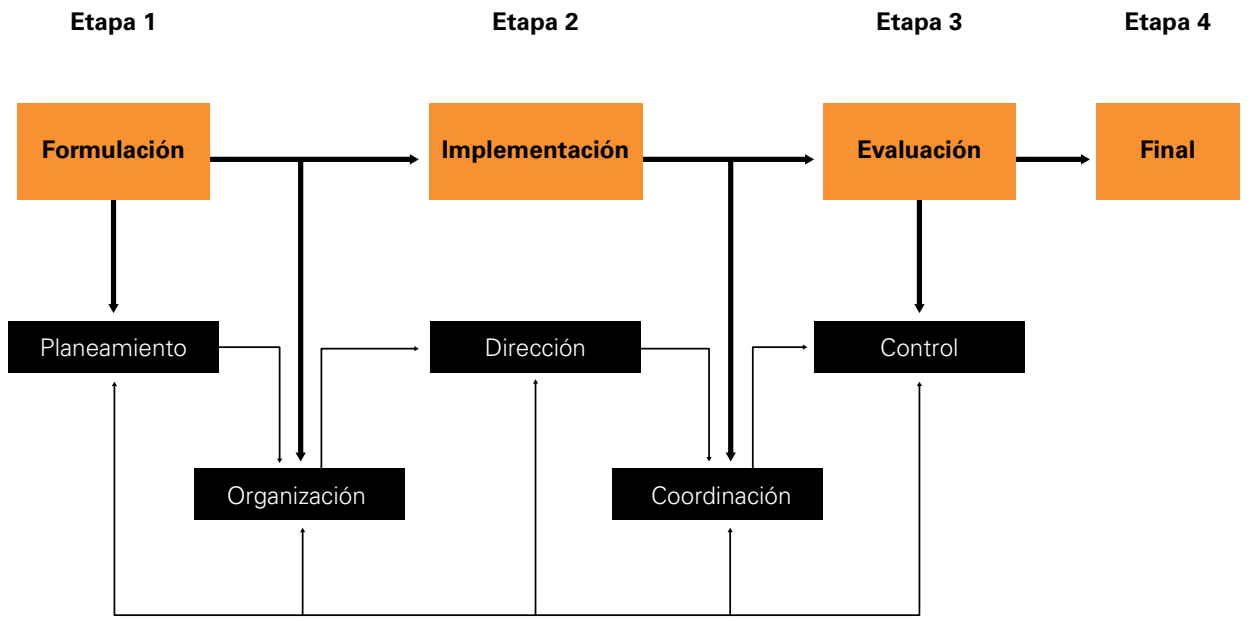

Fuente: D’Alessio Ipinza (2013:15)

Cabe precisar que en la década de 1950 se empleaban las palabras planificar, organizar, integrar al personal, dirigir y controlar; sin embargo, hoy en día, los procesos administrativos "se concentran en las cuatro actividades básicas: planificar, organizar, dirigir y controlar" (Robbins y De Cenzo 2002: 6).

Las tres primeras etapas que refiere D'Alessio son las mismas que considera David; sin embargo, este autor las considera en el concepto de administración estratégica: "La administración estratégica se define como el arte y la ciencia de formular, implementar y evaluar decisiones multidisciplinarias que permiten que una empresa alcance sus objetivos" (David 2013: 5). Según David, en la primera se definen la visión y misión de la organización, se realiza el diagnóstico interno y externo, y se definen los objetivos de largo plazo y estrategias. En la etapa de implementación se ejecuta lo formulado a través de la determinación de temas administrativos (objetivos anuales, políticas, asignación de recursos, administración del conflicto, alineación con la estructura, desempeño y remuneración, administración de la resistencia al cambio, cultura de apoyo a la estrategia, operaciones y recursos humanos) y funcionales (marketing, finanzas y contabilidad, investigación y desarrollo, y sistemas de información gerencial). Finalmente, en la etapa de evaluación estratégica, se miden los resultados y se retroalimenta el proceso de gestión estratégica (David 2013: 5-14). 
Figura 2: Modelo integral del proceso de administración estratégica

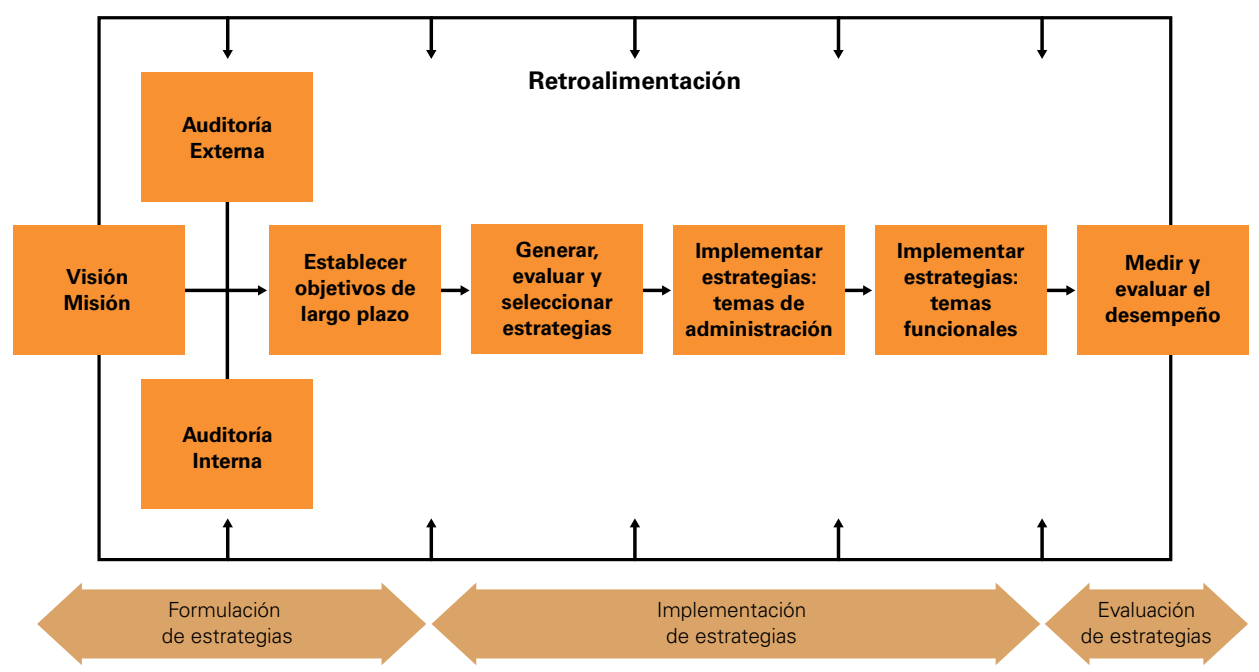

Fuente: Adaptado de David (2013: 14)

Como puede verse, el proceso estratégico es referido por los autores de diferente forma; sin embargo, incluyen de manera implícita el término estrategia. Según Porter, "la estrategia es lo que hará diferente a una organización, en particular brindando una ventaja competitiva [...], es encontrar una forma diferente de competir creando valor para el cliente, lo cual le permite a la compañía prosperar y lograr una rentabilidad superior [...], es hallar un lugar distintivo para que la organización dé valor..." (Porter 2012). Por otro lado, también se le considera como "la dirección y el alcance de una organización a largo plazo que permite lograr una ventaja en un entorno cambiante mediante la configuración de sus recursos y competencias, con el fin de satisfacer las expectativas de las partes interesadas" (Johnson y otros 2006: 10). David considera que las estrategias "son los medios a través de los cuales se alcanzarán los objetivos de largo plazo [...] son posibles cursos de acción que requieren de decisiones por parte de los altos directivos y de grandes cantidades de recursos de la empresa" (David 2013: 11). También se le considera como "[...] el conjunto de acciones relacionadas que los administradores toman para mejorar el desempeño de su compañía" (Hill y otros 2015: 3) y "conjunto de compromisos y acciones integrados y coordinados, diseñados para explotar las competencias centrales y lograr una ventaja competitiva" (Hitt, Ireland y Hoskisson 2015: 4).

En este punto se resalta nuevamente el concepto de ventaja competitiva visto en la sección anterior, relacionándolo particularmente con los cambios y las capacidades de las organizaciones para adaptarse a ellos. "Cuando una empresa puede hacer algo que las empresas rivales no pueden, o tienen algo que sus rivales desean, eso representa una ventaja competitiva" (David 2013: 8). Lo común es que una organización mantenga su ventaja competitiva por un tiempo, ya que sus rivales buscarán imitarla y minarla; en ese sentido, "no basta con sólo obtener una ventaja competitiva. Una empresa debe esforzarse 
para alcanzar una ventaja competitiva sostenida mediante: 1) su adaptación continua a los cambios en las tendencias y acontecimientos externos, y en las capacidades, competencias y recursos internos; 2) la efectividad en la formulación, implementación y evaluación de estrategias que capitalicen estos factores" (David 2013: 9). En ese sentido, Hitt y otros complementan:

Una compañía goza de ventaja competitiva cuando implementa una estrategia que crea más valor para sus clientes y que sus competidores no pueden copiar o cuya imitación les resulta demasiado costosa. Una organización no puede estar segura de que su estrategia ha producido una o varias ventajas competitivas útiles hasta que los competidores se han retirado o fracasado en su intento por imitar la estrategia. Además, las compañías deben tener presente que ninguna ventaja competitiva es permanente. La velocidad con la que los competidores adquieran las habilidades necesarias para replicar los beneficios de la estrategia de la empresa que crea valor determina el tiempo que durará su ventaja competitiva (2015: 5).

Por eso, es importante que las organizaciones desarrollen las capacidades de adaptarse y de ser efectivas en sus procesos de formulación, implementación y control. Con esto se fortalece el sostenimiento de su ventaja competitiva.

Por otro lado, en su libro Safari a la estrategia, Mintzberg presenta diez escuelas de pensamiento para la formulación de la estrategia, en la que cada una sostiene un punto de vista sobre el proceso estratégico (1999: 5):

1. La escuela de diseño: la estrategia como un proceso de concepción.

2. La escuela de planificación: la estrategia como un proceso formal.

3. La escuela de posicionamiento: la estrategia como un proceso analítico.

4. La escuela empresarial: la estrategia como un proceso visionario.

5. La escuela cognoscitiva: la estrategia como un proceso mental.

6. La escuela del aprendizaje: la estrategia como un proceso emergente.

7. La escuela de poder: la estrategia como un proceso de negociación.

8. La escuela cultural: la estrategia como un proceso colectivo.

9. La escuela ambiental: la estrategia como un proceso reactivo.

10. La escuela de configuración: la estrategia como un proceso de transformación.

Es decir que, dependiendo del enfoque o escuela de pensamiento, la estrategia y su formulación tendrán un matiz particular. Por ejemplo, en la escuela de aprendizaje, Mintzberg señala que la estrategia se formula a través de un proceso emergente en el que los estrategas, responsables del éxito o fracaso de una organización, aprenden a proceder con el tiempo (1999: 274). Este proceso dinámico puede apreciarse en la siguiente figura: 


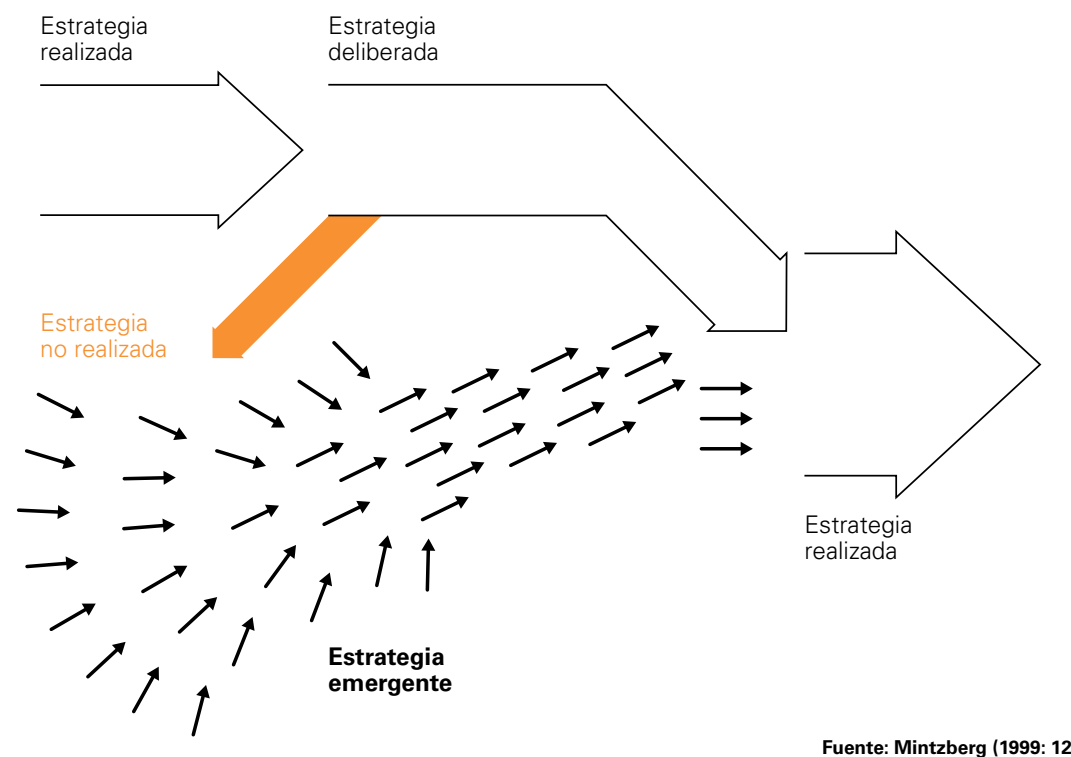

En ese proceso de aprendizaje, la estrategia deseada podría descartarse por alguna razón interna o externa y podrían surgir nuevas estrategias (emergentes) las cuales finalmente serán las realizadas. Este proceso dinámico puede plantear retos desde el punto de vista de la gestión del cambio para dar soporte a la ejecución de dicha estrategia.

Otro enfoque que ayuda a comprender el vínculo entre el proceso estratégico y la gestión del cambio es la visión estratégica basada en recursos (Hart 1995; Peteraf 1993; Wernerfelt 1984) que sostiene que las ventajas competitivas dependen de la correspondencia entre las capacidades organizacionales (internas) y las circunstancias cambiantes (externas) (Hart 1995). Las primeras se forjan a través de los recursos valiosos e insustituibles de la organización que forman características clave que son específicas de la organización, son socialmente complejos y tácitos; esta base permite el desarrollo de ciertas capacidades como la tecnología, diseño, compras, producción, distribución y servicio, con las cuales se logra la ventaja competitiva que puede destacarse por la estrategia de costo o diferenciación buscando ser la primera opción de compra para sus clientes, lo que garantiza sus ingresos en el corto, mediano y largo plazo (Hart 1995). Esta visión requiere un proceso estratégico que apoye a la organización de tal forma que evite que su ventaja competitiva sea copiada o esta quede obsoleta (Hart 1995).

Hart sostiene que tales recursos son invisibles y se basan en el aprendizaje práctico acumulado por la experiencia y refinado con la práctica (1995). Peteraf destaca cuatro elementos que permiten el logro de ventajas competitivas: la hererogeneidad de los recursos, los límites posteriores a la competencia, la movilidad imperfecta de los recursos y los límites previos a la competencia (1993). La heterogeneidad de los recursos organizacionales hace referencia a la diferencia que debe existir con aquellas otras organizaciones de la industria. Por otro lado, se debe recordar que los recursos pueden considerarse como una fortaleza o debilidad: pueden ser tangibles o intangibles organizacionales como la marca, 
el conocimiento, la tecnología, el personal, las máquinas, etc.; en general, lo importante es encontrar en qué circunstancias estos proporcionarán ventajas, expresadas en altos rendimientos, por periodos de tiempo prolongados (Wernerfelt 1984). Así, la formulación debe tener en cuenta los recursos organizacionales y la gestión del cambio también.

En línea con la visión basada en los recursos, Peng desarrolló el "trípode de la estrategia" que incluye tres perspectivas que permiten la creación de una estrategia que logre rendimientos mayores (Peng 2010):

\section{Figura 4: El trípode de la estrategia (tres perspectivas líderes en estrategia)}

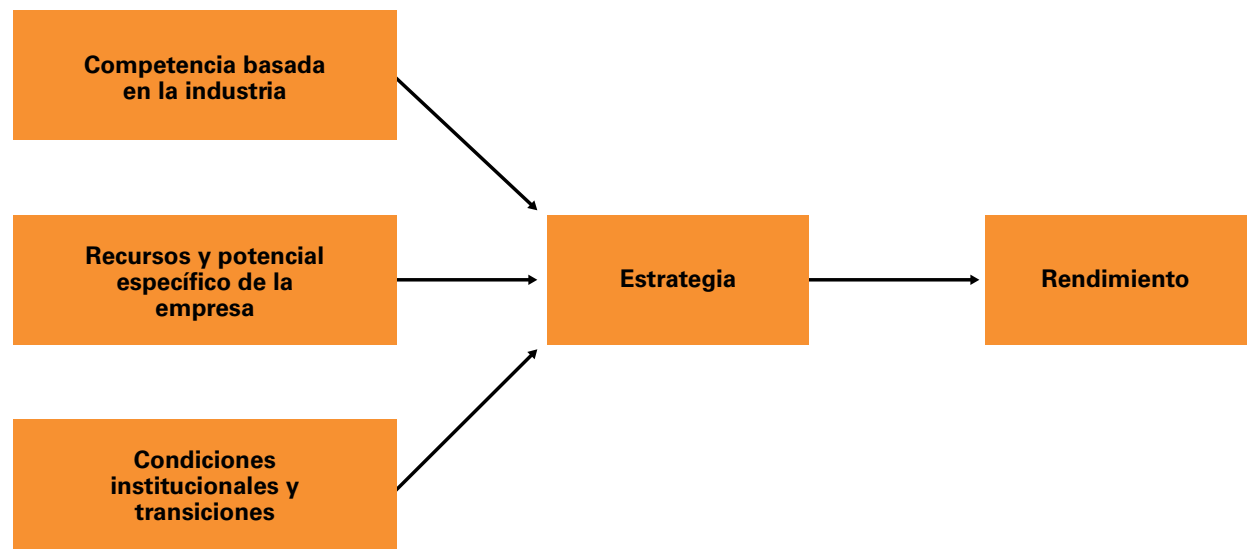

Fuente: Peng (2010: 15)

La visión basada en la industria indica que la estrategia debe examinar las cinco fuerzas competitivas de la industria (rivalidad entre compañías, amenaza de potenciales competidores, el poder de negociación de proveedores, el poder de negociación de clientes y la amenaza de sustitutos) y asegurar una posición menos vulnerable en relación con estos cinco elementos, concentrándose en las oportunidades y amenazas (Peng 2010: 15), mientras que la visión basada en los recursos se centra en las fortalezas y debilidades de la organización sosteniendo que las capacidades específicas de estas son las que diferencian a aquellas que son exitosas de las que fracasan (Peng 2010: 15). Por otro lado, "la visión basada en las instituciones alega que las fuerzas institucionales también proporcionan una respuesta a las diferencias en el desempeño de la firma" (Peng 2010: 16). Peng sostiene que las organizaciones deben "pensar globalmente y actuar localmente de manera simultánea. Es difícil imaginar que las firmas que no hacen su 'tarea' de conocer las diferentes reglas del juego informales y formales en los mercados extranjeros, emergerán como ganadoras en el mercado global" (2010: 16-17). Con estas últimas referencias se evidencia la necesidad de tener en cuenta no solo las dimensiones internas y externas en el proceso estratégico, sino la visión institucional que deben tener las organizaciones en la generación de estrategias que permitan generar una ventaja competitiva y así generar valor también.

Por otro lado, Hill y otros entienden el liderazgo estratégico "como la forma más efectiva de manejar el proceso de creación de estrategias de una compañía para generar una ventaja competitiva" (2015: 4). Los gestores siguen este proceso para escoger e im- 
plementar las estrategias que les permitan lograr sus ventajas competitivas y un desempeño superior: "La formulación de estrategias se refiere a la tarea de escoger estrategias, mientras que implementar las estrategias, se refiere a la tarea de ponerlas en práctica, lo cual supone diseñar, entregar y sostener productos, mejorar la eficiencia y eficacia de las operaciones, y diseñar la estructura organizacional de una compañía, sus sistemas de control, su cultura" (Hill y otros 2015: 4). Este proceso puede verse a continuación:

Figura 5: El liderazgo estratégico y el proceso de administración estratégica

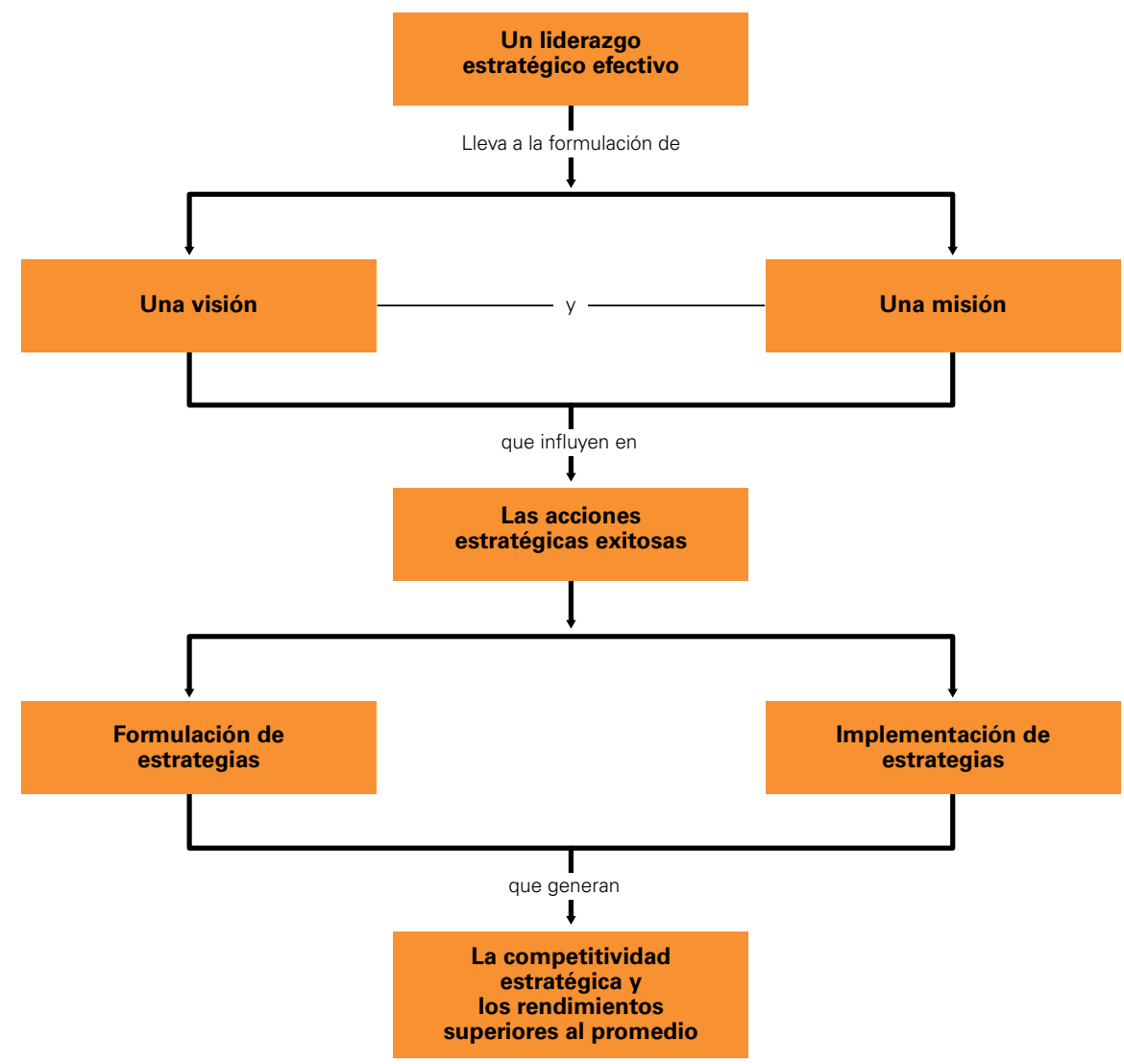

Fuente: Hitt y otros (2015: 371)

“El liderazgo estratégico se refiere a la capacidad de anticipar, tener una visión, mantener la flexibilidad y atribuir facultades a otros con el propósito de crear cambios estratégicos conforme se necesiten" (Hitt y otros 2015: 371). Esta capacidad es determinante para la formulación de una visión y misión que influyen en acciones estratégicas exitosas, integrando la formulación e implementación de estrategias, en busca del logro de la competitividad y rendimiento superior. "El liderazgo estratégico es multifuncional por naturaleza e implica administrar por medio de otros, administrar una organización completa y no una subunidad funcional, así como manejar el cambio que no cesa de incrementar en la economía global" (Hitt y otros 2015: 371). Los líderes estratégicos, siguiendo a los mismos autores, deben "aprender a influir en forma efectiva en la conducta humana, muchas veces en entornos inciertos" (2015: 371). Adicionalmente, los líderes estratégicos deben tener 
la capacidad para atraer y administrar el capital humano y deben apoyar el entorno en el cual se desempeñan sus stakeholders (2015: 372). "La responsabilidad principal de un líder estratégico efectivo está en la cima, en particular en el CEO [...]. El liderazgo estratégico es una forma compleja y fundamental de liderazgo. Cuando no hay líderes estratégicos efectivos no es posible formular ni implementar estrategias que sirvan para tener rendimientos superiores al promedio" (Hitt y otros 2015: 372).

En adelante, se usará el término proceso estratégico en referencia a la formulación, implementación y evaluación de estrategias que permitan que la organización logre una ventaja competitiva sostenible en el tiempo. Estos planteamientos permitirán definir un modelo de gestión del cambio centrado en planificar (definir objetivos, estrategias, etc.), organizar (dimensiones estructurales), dirigir (considerando los temas administrativos y funcionales planteados por David) y controlar (evaluando todas las etapas secuenciales de manera permanente) de forma sistémica y generando valor compartido, teniendo en cuenta el proceso de aprendizaje que implica el desarrollo de estrategias emergentes, la visión basada en recursos, en la competencia basada en la industria (elementos externos) y en las condiciones institucionales. Adicionalmente, se complementará este concepto con la retroalimentación y seguimiento, y, por supuesto, el liderazgo estratégico será necesario en este proceso.

\section{4. ¿Qué es la gestión del cambio?}

En el contexto del proceso estratégico, muchos autores sugieren que la gestión del cambio es como una respuesta a dificultades en el proceso de cambio de estrategia: “El cambio estratégico es aquel que se produce como consecuencia de las estrategias que escoge e implementa una compañía" (Hitt y otros 2015: 371). Johnson y otros señalan que hay un "supuesto implícito sobre la tendencia hacia la inercia y la resistencia al cambio" entre los individuos de una organización (2006: 502). Las personas tienden a aferrarse a las condiciones actuales, lo cual suele marcar la pauta de una "desviación estratégica" (2006: 502). Es en la segunda etapa, la de implementación de estrategias, donde David hace énfasis en la necesidad de administrar el cambio:

Ninguna organización o individuo puede escapar del cambio. Pero pensar en el cambio angustia a las personas, pues temen la pérdida económica, los inconvenientes, la incertidumbre y la ruptura de los patrones sociales normales. Casi cualquier cambio en la estructura, la tecnología, personas o estrategias tienen el potencial de desestabilizar los patrones de interacción confortable. Por esta razón, las personas se resisten al cambio. El proceso mismo de administración estratégica puede imponer cambios importantes a los individuos y procesos. Reorientar la organización para ayudar a las personas a pensar y actuar de manera estratégica no es una tarea fácil (David 2013: 234).

Johnson y otros indican que el cambio estratégico se produce de arriba abajo; “los altos directivos deciden la estrategia, planifican cómo se va a llevar a la práctica y, después, de alguna manera, realizan los cambios necesarios" (2006: 502). Sin embargo, también 
destacan el rol de los directivos intermedios y de sus subordinados en la gestión del cambio. Adicionalmente, estos autores ponen en evidencia la necesidad de un plan que vincule el cambio estratégico con las operaciones:

Para que el cambio tenga éxito es necesario que esté relacionado con los aspectos estratégicos y operativos cotidianos de la organización. Esto pone énfasis en la importancia de traducir el cambio estratégico en planes de recursos detallados, tareas clave, y en la forma en que se dirige la organización a través de procesos de control, pero también de cómo se comunica el cambio a través de las actividades cotidianas de la organización (Johnson y otros 2006: 502).

Para Daft (2011) el cambio es impulsado por las fuerzas del entorno:

Las poderosas fuerzas asociadas con la avanzada tecnología, la integración económica nacional, la madurez de los mercados domésticos y el cambio al capitalismo en las regiones antes comunistas, han traído consigo una economía globalizada que afecta a todas las empresas, desde la más grande hasta la más pequeña, creando más amenazas y oportunidades. Para reconocer y administrar las amenazas y aprovechar las oportunidades, las empresas actuales pasan por sorprendentes cambios en todas las áreas de sus operaciones (2011: 412).

Daft hace énfasis en que el cambio ya no es más gradual y poco frecuente. Hoy en día este plantea cada vez más retos, ya que se da de manera constante y solo las empresas que desarrollen pasión por crear cambios tendrán éxito en sus industrias (2011). Es así que la gestión del cambio se vuelve una necesidad también por los retos intrínsecos que plantea a las organizaciones:

Aunque las circunstancias concretas de cada empresa son la razón de algunos de los problemas, las dificultades generales comparten, al menos, una raíz común: los directivos y los empleados tienen una opinión muy diferente del cambio. Ambos grupos saben que la visión y el liderazgo son el motor del éxito de un cambio, pero son muy pocos los líderes que saben de qué forma se comprometen las personas con el cambio para hacer que éste sea posible. Los directivos de alto nivel ven el cambio como una oportunidad de reforzar la empresa mediante la coordinación de las operaciones con la estrategia, de asumir nuevos retos y riesgos profesionales y de progresar en su carrera. Sin embargo, para muchos empleados entre los que hay que incluir a los directivos de rango intermedio, el cambio no es algo buscado, ni bienvenido. Crea trastornos y es inoportuno, trastoca el equilibrio (Strebel 2000: 177).

La necesidad de gestionar el cambio surge como aporte para cerrar estas brechas que pueden existir entre la formulación e implementación estratégica y también para minimizar las resistencias que puedan surgir y que pueden expresarse de diversas formas. 
Para David, la resistencias constituyen la mayor amenaza para el éxito en la implementación estratégica (2013). La resistencia puede verse en las organizaciones como "saboteo a las máquinas de producción, ausentismo, acusaciones o quejas infundadas e indisposición a cooperar" (David 2013: 234). Usualmente, esta resistencia se debe a que las personas no entienden lo que está pasando o por qué se están produciendo los cambios. En esta parte se va intuyendo una necesidad de gestionar las comunicaciones. “Los empleados quizá sólo necesiten información precisa. La implementación exitosa de la estrategia depende de la capacidad de los gerentes de desarrollar un clima organizacional propicio para el cambio [...]. La resistencia al cambio puede surgir en cualquier etapa o nivel del proceso de implementación" (David 2013: 234).

\section{Fuerzas, tipos, elementos y modelos de cambio}

Según Daft, pueden haber varios tipos de cambios en las organizaciones a propósito de las fuerzas que ocurran en su entorno externo (oportunidades o amenazas, que tienen su origen en los cambios globales, de la competencia y de los diversos mercados donde la organización se desenvuelve): cambio en la estructura, cambio estratégico, cambio en la cultura, administración bien informada, planeación de los recursos empresariales, programas de calidad, fusiones, joint ventures, consorcios, organizaciones horizontales, equipos, redes, nuevas tecnologías y productos, nuevos procesos de negocio, e-business y organizaciones que aprenden (2011: 413). Estas fuerzas impulsoras, así como los tipos de cambio que pueden generar, pueden verse en la siguiente figura:

Figura 6: Fuerzas que impulsan la necesidad de un importante cambio organizacional

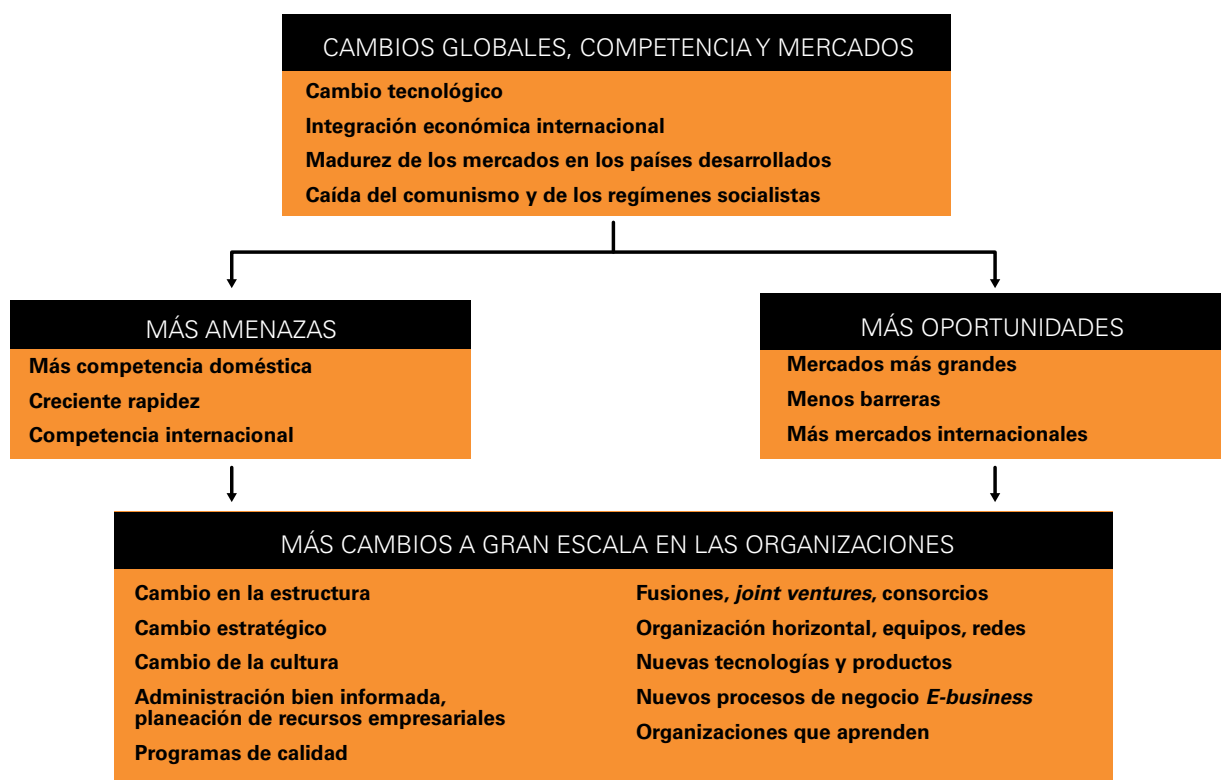

Fuente: Daft (2011: 413) 
Daft resume los tipos de cambio en cuatro: cambios en la tecnología, que pueden ser modificaciones en el proceso de producción o en su base de conocimiento; cambios en el producto y servicio, que pueden incluir adaptaciones, mejoras o líneas nuevas; cambios en la estrategia y estructura, que incluyen la supervisión y administración de la organización; y cambios en la cultura, por ejemplo la transformación de los valores, actitudes, conductas, entre otros (2011: 413-414).

Otra perspectiva que permite un acercamiento a la tipología de cambio es la planteada por Quinn y Voyer (1997) en el contexto de la formulación estratégica: el incrementalismo lógico. "Los procesos de los cambios estratégicos suelen ser fragmentados, evolutivos e intuitivos. La estrategia real evoluciona conforme las decisiones internas y los hechos externos fluyen juntos y crean un consenso nuevo, compartido en general, para la acción" (1997: 139). De un resumen de los resultados de un estudio sobre los procesos de cambio que presentan los autores, se puede resaltar que "las estrategias efectivas suelen surgir en forma incremental, de acuerdo con las oportunidades, como subsistemas de la actividad de la organización (por ejemplo, adquisiciones, despojos, reorganizaciones grandes, incluso planes formales) y se entremezclan dentro de un patrón coherente" (Quinn y Voyer 1997: 140), resaltando el carácter evolutivo e intuitivo del cambio impulsado por la generación de las estrategias, evidenciándose la escuela de aprendizaje de Mintzberg (1999: 5). Asimismo, indican que "la lógica que sustenta el proceso es tan sólida que podría ser el mejor enfoque que se pueda recomendar para la creación de estrategias en compañías grandes" (Quinn y Voyer 1997: 140). Es de esta forma que acuñan el término incrementalismo lógico haciendo referencia a una "técnica administrativa activa, efectiva y con un propósito, que sirve para integrar y perfeccionar los aspectos analíticos y conductuales de la creación de estrategias" (Quinn y Voyer 1997: 140).

En este contexto, Quinn y Voyer señalan que existen cambios débiles, es decir, pocos "se prestan para hacer modelos cuantitativos y análisis financieros" (1997: 140). Algunos de ellos son el diseño de la estructura de una organización, el estilo de gestión, las relaciones externas de la empresa, su capacidad de innovar, las consecuencias del crecimiento organizacional en la motivación de los empleados, los cambios de valores y expectativas, y los cambios en la tecnología (1997: 140).

Siguiendo la tipología de cambios, para Tushman, Newman y Romanelli (1997) existen los cambios convergentes que suelen ser incrementales; sin embargo, también hay cambios que rompen con la estructura: "El cambio incremental es compatible con la estructura existente de una empresa y es reforzado durante un periodo de dos años. En contraste, el cambio que rompe la estructura es abrupto, doloroso para los particulares y, con frecuencia, resistido por la vieja guardia" (1997: 419). Probablemente, por su naturaleza, estos últimos requerirán de una gestión del cambio de mayor envergadura.

Por otro lado, para Johnson y otros los elementos clave para la gestión del cambio estratégico son el diagnóstico de la situación de cambio, los agentes de cambio, las palancas de cambio y los inconvenientes que se pudieran presentar en el proceso de cambio (2006: 503). 


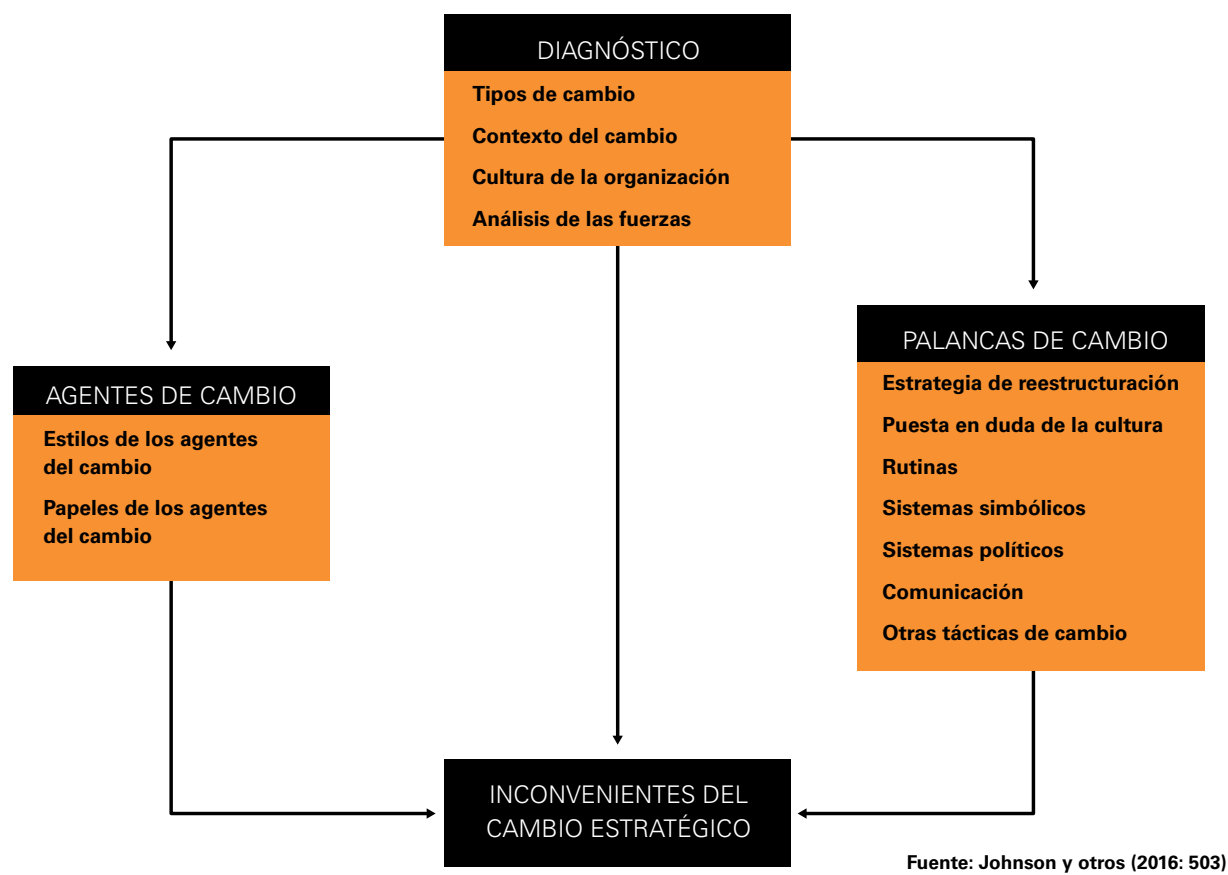

Más adelante, se verá cómo gran parte de estos conceptos se incorporarán en el modelo propuesto. A continuación, se desarrollarán los elementos planteados en la figura previa. El diagnóstico de la situación de cambio hace referencia a la necesidad de comprender por qué es necesario que el cambio ocurra, así como también la base estratégica y su ventaja competitiva, la misma que tiene su origen en el propósito estratégico de la organización, las direcciones y métodos de desarrollo de la estrategia, y los cambios generados en las estructuras, procesos, relaciones, recursos y actividades necesarios para que la nueva estrategia se ponga en práctica (Johnson y otros 2006: 504-513).

Los agentes de cambio hacen referencia al rol que desempeñan las personas para gestionar el cambio, cómo lo hacen (estilos: educar y comunicar, colaborar y participar, intervenir, dirigir y coaccionar) y los papeles que deben tener los líderes del proceso, los directivos intermedios, los terceros (asesores) y los externos interesados (Johnson y otros 2006: 513-521).

Las palancas de cambio muchas veces pueden ser elementos de la cultura y pueden ayudar a proteger la forma actual de hacer las cosas (barreras del cambio) o contribuir para cambiarlas (facilitadores del cambio). Algunas palancas pueden ser: la reestructuración, que apunta a un cambio rápido con énfasis en la reducción de costos y/o generación de ingresos; la mentalidad, que puede poner en duda los actuales paradigmas, aprendiendo a cuestionar lo que se da por sentado; las rutinas o formas en las que se hacen las cosas, 
que pueden convertirse en bloqueos al cambio; los procesos simbólicos, que pueden estar representados por objetos, acontecimientos, actos o personas; los sistemas políticos, cuando es necesario comprender la estructura de poderes en la organización, los grupos interesados y aquellos que se oponen al cambio, las alianzas y redes, entre otros; los estilos de comunicación, es decir sus medios, participación, retroalimentación, aspectos emocionales, etc.; y evaluar otras tácticas de cambio, como la oportunidad para promocionar el cambio, la planificación de pérdidas de puesto de trabajo (si fuera el caso) y/o estimular el logro de éxitos tempranos, entre otros (Johnson y otros 2006: 521-536).

Finalmente, los autores indican que "un exhaustivo estudio de Lloyd Harris y Emannuel Ogbonna identifica una serie de resultados involuntarios de los programas de cambio" (citado en Johnson y otros 2006: 536), tales como: la ritualización del cambio, siendo considerado como un ritual sin significado; los procesos de cambios "secuestrados", refieriéndose al uso del cambio para otros fines; la erosión, cuando hay muchas dificultades que minan el proceso de cambio; la reinvención, cuando el cambio se reinterpreta teniendo en cuenta la cultura previa; el cuestionamiento o falta de credibilidad de los defensores del cambio, porque no tienen en cuenta las necesidades de los interesados; la falta de atención a los símbolos del cambio; los esfuerzos sin coordinar y sin controlar, los cuales producen incoherencias; y el cumplimiento falso, en el que las personas aparentan asumir los cambios (Johnson y otros 2006: 536-538).

Teniendo en cuenta lo previamente desarrollado, es oportuno indicar que existen muchas propuestas que ayudan a entender cómo abordar la gestión del cambio en las organizaciones. Sin embargo, algunas son más complejas que otras, o más o menos aplicables a las diversas realidades organizacionales. A continuación, se describirán algunas que serán útiles para el modelo planteado en este artículo.

\subsection{Estrategia de cambio forzado, estrategia de cambio educativo y estrategia de cambio racional o egoísta}

David sostiene que estas tres estrategias son las más usadas. La estrategia de cambio forzado se basa en la autoridad. Consiste en dar órdenes y hacerlas cumplir. "Esta estrategia tiene la ventaja de ser rápida, pero adolece de bajo nivel de compromiso y alta resistencia" (2013: 234). La resistencia de cambio educativo consiste en informar a las personas sobre la necesidad de cambio. "La desventaja de una estrategia de cambio educativo es que la implementación se vuelve lenta y difícil" (2013: 235). La tercera estrategia, de cambio racional o egoísta, se basa en el convencimiento que se genera en los individuos respecto a que el cambio los beneficiará personalmente. Cuando esto funciona, la implementación estratégica puede ser "relativamente fácil. No obstante, la implementación de cambios rara vez será en beneficio de todos" (2013: 235).

Según Duncan, la estrategia de cambio racional o egoísta, la más recomendada, se caracteriza por cuatro etapas:

En la primera [etapa], se invita a los empleados a participar en el proceso de cambio y en los talleres de la transición; la participación permite que todos expresen sus opiniones, se sientan parte del proceso de cambio y que identifiquen sus 
propios intereses en relación con el cambio recomendado. En la segunda, se requiere cierta motivación o incentivo para el cambio; el egoísmo puede ser el motivador más importante. En la tercera etapa, la comunicación es necesaria de manera que la gente pueda comprender la finalidad de los cambios. Dar y recibir retroalimentación es el cuarto paso: todos disfrutan saber cómo van las cosas y cuánto se ha progresado (citado en David 2013: 235).

David complementa esta metodología indicando que el cambio es algo común en las organizaciones; lo que varía con el tiempo es su velocidad, magnitud y dirección, de acuerdo con la industria y al tipo de organización. "Los estrategas deben esforzarse en crear un ambiente laboral en el que se reconozca el cambio como necesario y benéfico, de manera que las personas puedan adaptarse con mayor facilidad a él" (2013: 235). El proceso de cambio puede presentar menos resistencias cuando se involucra a los individuos afectados en la decisión de cambio, así como en las decisiones de cómo implementarlo. También se sugiere incluirlos en talleres de capacitación y desarrollo, y comunicar de manera efectiva la necesidad de cambiar. Finalmente, David señala que las organizaciones exitosas deben anticiparse a los cambios antes que reaccionar ante ellos (2013).

El enfoque de David resulta interesante en términos de que las personas cambiarán porque les resulta conveniente: se involucra al sujeto de cambio en el proceso y se le mantiene informado y retroalimentado. Adicionalmente, se rescata que con estas consideraciones se presentarán menos resistencias.

\subsection{Incrementalismo lógico}

Quinn y Voyer plantean que los gestores suelen recurrir a un proceso de aprendizaje flexible y experimental cuando administran cambios complejos en las estrategias. El modelo que sugieren a partir del concepto del incrementalismo lógico contempla las siguientes acciones y/o características: los gerentes, al tener acceso a fuentes de información internas y externas, pueden y deben ser capaces de preveer las necesidades de cambio antes que los sistemas formales de información lo sugieran; también deben estimular psicológicamente a las personas para generar procesos de cambio y darles señales de credibilidad respecto a esa intención para generar confianza (1997: 143).

Los gestores también deben ser capaces de generar espacios y tiempos para "despertar la conciencia de la organización" (Quinn y Voyer 1997: 143) que sirva para la promoción de la discusión en la organización que ayude a encontrar soluciones nuevas y tener más y mejor información para la toma de decisiones.

Otra consideración del modelo incluye la contemplación de planes operativos, cambios de tácticas o programas cortos, ya que estos suelen tener niveles de resistencia menores en comparación con los cambios estratégicos, por lo que se sugieren para incrementar el éxito del proceso de cambio. También se incluye la ampliación del apoyo político a través de los líderes de las diversas áreas, grupos o comités con el propósito de conseguir aliados de soporte al cambio; esto ayuda a crear consenso, mejora la calidad de las decisiones y se promueve el apoyo e innovación, sobre todo cuando los resultados son adversos (Quinn y Voyer 1997: 143). 
Otro punto importante es que se debe evitar prescindir de los gerentes que representen alguna oposición al proceso de cambio, a menos que sea estrictamente necesario, ya que su experiencia es importante y podría requerirse; de ser necesario, se debe superar su oposición de preferencia por persuasión, democracia, neutralización y/o llevarlos hacia puestos que no sean críticos y/o con menos influencia para que no afecten en el proceso de cambio. En el caso en que los ejecutivos sean muy intransigentes, es probable que la mejor opción sea sugerirles que abandonen la organización (Quinn y Voyer 1997: 144).

La flexibilidad es crucial para enfrentarse a los imprevistos que puedan surgir. Para ser flexibles y poder responder oportunamente, es necesario el estudio de todos los elementos que permitan la adecuada planificación de las contingencias. Los planes preformulados a veces no pueden usarse debido a que los factores ahí presentes pudieran no expresarse en la realidad empresarial (Quinn y Voyer 1997).

La espera paciente es también un ingrediente que considera el incrementalismo lógico. Esperar una circunstancia o una oportunidad puede ser crucial para el éxito del proceso de cambio. Quinn y Voyer sugieren que los gestores no se comprometan con una solución específica, sino, más bien, que promuevan la capacidad creativa de la organización. Se sugiere la promoción de proyectos pequeños que ayude "para probar opciones, crear habilidades o lograr el compromiso con varias opciones posibles" (Quinn y Voyer 1997: 144). Los gestores deben proporcionar metas amplias, un clima organizacional favorable, apoyo flexible de recursos sin hacer notar públicamente su compromiso. Esta acción mitiga la atención que el personal le pueda dar a un determinado proyecto y su identificación con él. Otra opción que plantean los autores es incitar alternativas positivas, ir en contra de aquellas que consideren negativas o eliminar las menos ventajosas (Quinn y Voyer 1997: 144).

En algún punto del proceso, se debe centrar el enfoque. Este momento se alcanza cuando, finalmente, se ha llegado a un consenso en la organización, cuando se cuenta con toda la información que se requiere. Ese es el punto en el que los líderes deben hacer uso de su prestigio o poder. "Saber cuándo cristalizar los puntos de vista y cuándo mantener opciones abiertas es un verdadero arte de la administración de estrategias" (Quinn y Voyer 1997: 144). Una vez que se llega a este punto y se ha logrado la aceptación del cambio, es necesario formalizar el compromiso con él. Enseguida, se anuncia la decisión públicamente, se plantea el proyecto, se asignan presupuestos, sistemas de control, etc., y cómo todo este proceso de cambio contribuirá con los objetivos estratégicos planteados (Quinn y Voyer 1997: 144).

El modelo del incrementalismo lógico no termina. Quinn y Voyer indican que es un proceso dinámico, ya que siempre surgirá una nueva estrategia que puede presentar más o menos niveles de resistencia. Los gestores deben tener la capacidad de estimular nuevamente la generación de cambios en la cúspide de la organización a fin de conservar la capacidad de adaptación que debe tener toda organización. Esta actividad es desgastante, pero indispensable para la oganización (1997).

Finalmente, estos autores señalan que todo este proceso no es lineal. Los pasos descritos previamente responden a una secuencia en la creación de una estrategia; sin embargo, las etapas normalmente no son secuenciales. El proceso es tan continuo y permanente, indican, que, incluso a veces, puede resultar complicado darse cuenta cuando se toma una decisión específica (1997: 145). 
Estos autores rescatan el hecho de que la organización debe estar atenta a lo que pasa en su contexto y debe fomentar la introducción permanente de iniciativas de cambio, de nuevas formas de hacer las cosas; también deben elaborar planes operativos de corto plazo, ya que estos tienen un nivel de resistencia menor; debe ser flexible y paciente y ser capaz de detectar la oportunidad del cambio, sin perder de vista que este es móvil y permanente.

\subsection{Los ocho pasos de la gestión del cambio de arriba abajo}

John Kotter publicó en 1995 un artículo en la Harvard Business Review sobre los problemas del cambio estratégico radical en el que atribuía a los altos ejecutivos la falta de identificación de la "secuencia necesaria para dirigir estos cambios" (citado en Johnson y otros 2006: 539). Los ocho pasos que propuso son (Johnson y otros 2006: 539):

1. Crear el sentido de urgencia a partir de las realidades competitivas y del mercado, con una clara discusión sobre las crisis potenciales o las principales oportunidades.

2. Crear una poderosa coalición directriz: es probable que incluya a altos ejecutivos, pero también a otras partes interesadas clave; y animar a este grupo a que colabore como un equipo.

3. Crear una clara visión para dirigir el esfuerzo del cambio y desarrollar claras estrategias para conseguirlo.

4. Comunicar la visión, utilizando múltiples vehículos, y asegurarse de que el comportamiento de la coalición directriz sea acorde con la visión.

5. Delegar poder a otros para que actúen en función de la visión: que supriman los obstáculos del cambio, que cambien los sistemas o estructuras que minan la visión, y que fomenten la aceptación de riesgos y de ideas, actividades y acciones no tradicionales.

6. Planificar y crear ventajas a corto plazo: la transformación estratégica puede llevar años, pero la gente tiene que ver resultados rápidamente.

7. Consolidar las mejoras y avanzar en los cambios: cuando se ha logrado la credibilidad del cambio hay que cambiar más estructuras, sistemas y políticas y promocionar a los que aplican la visión y reforzar el proceso de cambio.

8. Institucionalizar los nuevos planteamientos: a medida que se produce el cambio y se asienta, hay que demostrar que ha ayudado a mejorar el rendimiento y garantizar que la próxima generación de altos directivos personifique esta visión.

Balogun y Johnson "ponen en duda el grado en que los altos directivos pueden gestionar realmente el cambio siguiendo un planteamiento de arriba abajo [...]. Concluyen que, aunque la alta dirección creía que estaba dejando clara cuál era la estrategia pretendida, el cambio se produjo realmente de la siguiente manera" (citado en Johnson y otros 2006: 539): Ios directivos intermedios interpretaron las iniciativas de cambio según sus modelos, responsabilidades, conversaciones y rumores, mientras que los altos directivos estaban alejados, lo cual impidió que estos influyan en los primeros y que creen cambios distintos a cómo se han dictado desde la cúpula organizacional. Por esto, los autores recomiendan tener claro que la visión se interpretará de distintas maneras, que los directores 
intermedios tendrán su interpretación, que se supervisen los resultados del cambio, que se atiendan las iniciativas de cambio de los niveles inferiores y que hay que estar preparados para un ajuste de la intención estratégica (citado en Johnson y otros 2006: 539).

El modelo planteado por Kotter ha sido recogido por varios autores durante años. Los pasos que plantea son altamente relevantes. Particularmente se considera que en la delegación de poder para el cambio se resalta el rol de los agentes del cambio ya que ellos pueden apoyar en el acortamiento de la brecha que puede existir entre los altos directivos, los directivos intermedios y los demás miembros de la organización.

\subsection{La gestión del cambio desde la gestión de proyectos}

Otros autores consideran que la gestión del cambio puede hacerse bajo un enfoque de gestión de proyectos, teniendo en cuenta las siguientes particularidades: estos son a corto plazo, con efectos concretos y tangibles, susceptibles de ser extendidos, reducidos o cerrados, ejecutados por un grupo heterogéneo, con personas con las capacidades requeridas, dirigidos por un facilitador, implementados sobre la base de un plan con actividades y recursos definidos, ejecutados con personas seleccionadas y conectados y coordinados con otros proyectos (Barroso y Delgado 2007). Con este enfoque práctico, se conseguiría descomponer la complejidad del cambio en tareas específicas, en periodos definidos y con responsables directos; el patrocinador del cambio mejora la cooperación y coordinación; al recibir recursos, el proyecto de cambio recibe mayor importancia, la estructura del proyecto incorpora a los interesados y el proyecto conlleva una estructura de seguimiento y control que permite una revisión periódica que facilite corregir el rumbo (Barroso y Delgado 2007).

Esta última propuesta sugiere un modelo de gestión útil y práctico para su implementación. De hecho, la gestión de proyectos es una práctica muy habitual en las organizaciones por las ventajas señaladas y se apoya en reuniones de seguimiento y retroalimentación que permiten un mejor cumplimiento de los plazos planteados. En el Anexo (Caso de aplicación) puede verse cómo se aplicó este enfoque en una organización colombiana.

\subsection{LaTeoría U}

El doctor Otto Scharmer, profesor titular del Instituto Tecnológico de Massachusetts (MIT, por sus siglas en ingles), colega de Peter Senge y facilitador de procesos de innovación y cambio en empresas y sistemas sociales, desarrolló la Teoría U sobre la base de su experiencia con algunos líderes e innovadores más destacados del mundo mostrando cómo los grupos y las organizaciones pueden desarrollar siete capacidades de liderazgo que les permitan crear un nuevo futuro, en un mundo en el que abundan los problemas y se hace necesaria una nueva capacidad de liderazgo colectivo para enfrentar los retos de una forma más consciente, intencional y estratégica, a través de un concepto llamado "presencing" (en inglés) que combina las palabras presenciar y sentir, percibir (2007).

Scharmer sostiene que "la causa de nuestro fracaso colectivo es que somos ciegos a la dimensión más profunda del liderazgo y el cambio transformador [...] En el ámbito de la administración (management) y liderazgo del cambio transformador, sabemos muy poco de esa dimensión interior y las técnicas específicas para mejorar el desempeño 'des- 
de dentro' [...] esta falta de conocimiento se constituye en un 'punto ciego' en nuestra manera de abordar el liderazgo y la gestión" (2007: 3-4). En este sentido, Scharmer sostiene que hay cuatro estilos de escucha que determinan el liderazgo exitoso, ya que este depende de la calidad de atención e intención que un líder tiene frente a una situación: 1) descargando, donde uno confirma lo que sabe; 2) hechos, donde se enfoca en diferenciar lo que uno conoce de lo que no; 3 ) empática, donde se abre el corazón para conectarse con el interlocutor; y 4) generativa, donde se produce el cambio ya que se logra un estado de conexión al origen profundo del conocimiento; así, para ser líderes efectivos, se debe entender primero el espacio interno desde el cual se actúa (2007: 4-7).

Estas cuatro estructuras de ámbitos de atención se trasladan a cuatro maneras diferentes de actuar (metaprocesos básicos del ámbito social) afectando la forma de comunicarse de los grupos, instituciones y sistemas: 1) pensar (ámbito individual), 2) conversar (ámbito grupal), 3) estructurar (ámbito institucional) y 4) coordinar ecosistemas (ámbito de sistemas globales) (Schamer 2007: 8).

\begin{abstract}
Albert Einstein señaló que los problemas no pueden ser resueltos a través del mismo nivel de conciencia que los creó. Si nosotros enfrentamos nuestros retos del siglo XXI con una mentalidad reactiva que refleja primordialmente las realidades de los siglos 19 y 20 (ámbitos 1 y 2), acrecentaremos la frustración, el cinismo y la ira. En todos los metaprocesos vemos la necesidad de aprender a responder desde un origen generativo (ámbito 4) (Schamer 2007: 8).
\end{abstract}

El desafío consiste en avanzar de respuestas reactivas y soluciones rápidas (ámbitos 1 y 2) a respuestas generativas que aborden la raíz sistémica de los problemas (ámbitos 3 y 4); para lograrlo, se debe pasar por un proceso de cinco movimientos que representa un viaje hacia una "íntima conexión con el mundo y avanzar a un lugar de conocimiento que surge desde adentro, para así hacer realidad lo nuevo, lo cual significa descubrir el futuro a través del hacer" (Schamer 2007: 8-9). Esta lógica se puede observar en la siguiente figura:

Figura 8: La U como un proceso en 5 movimientos

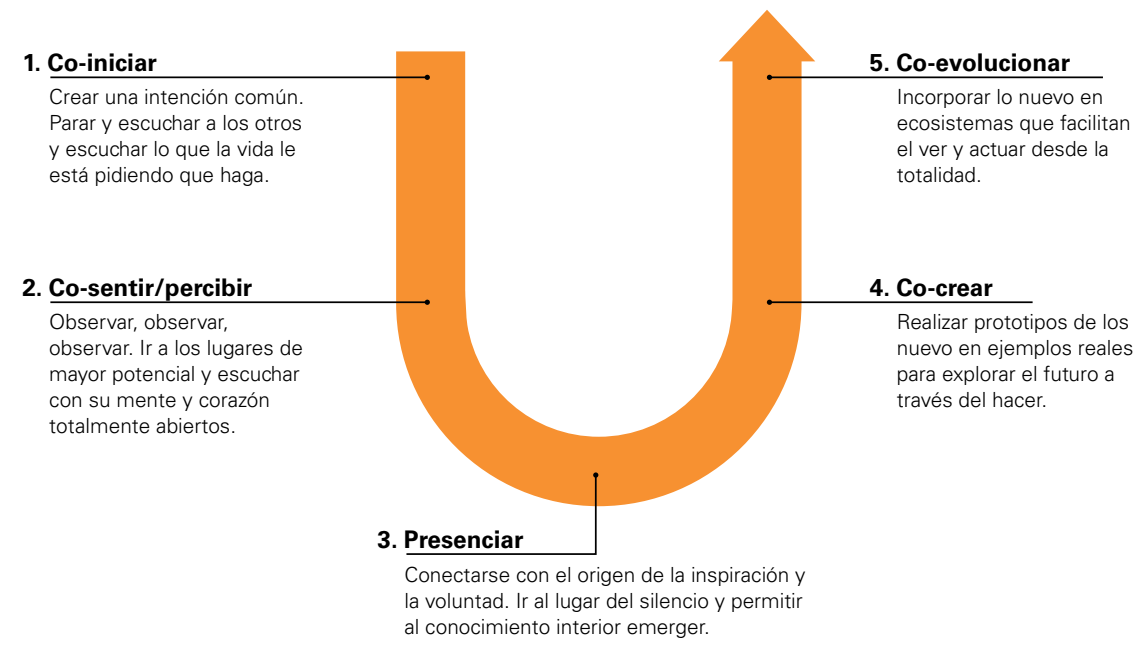


La etapa 1 se da al inicio de cada proyecto: una o varias personas se reúnen con el propósito de marcar la diferencia en una situación para ellos y su comunidad involucrando a más personas conformando un equipo motor que practica la escucha profunda. Dado que el factor que limita el cambio transformador no es la falta de ideas, sino la falta de la habilidad de sentir/percibir, el autor de la Teoría $U$ sostiene que en la segunda etapa es importante ver de manera profunda, aguda y colectiva. Además, comenta que cuando se trata de "organizar el manejo del conocimiento, estrategia, innovación y aprendizaje [...] delegamos el trabajo de campo a los expertos, consultores y profesores para que ellos nos expliquen cómo funciona el mundo" (Schamer 2007: 10). Esto podría ser recomendable para problemas sencillos, pero no para las actividades core del negocio. La percepción de estos asuntos debe ser inherente a los miembros del sistema: "Sin un vínculo directo con el contexto de una situación, no podemos aprender a ver y actuar de manera efectiva" (Schamer 2007: 11). En esta etapa es importante llegar a la observación profunda de manera colectiva, yendo más allá de los límites, "cuando este sentir/percibir ocurre, el grupo como un todo puede ser las oportunidades que emergen y las principales fuerzas sistémicas en juego" (Schamer 2007: 11). En la tercera etapa, la base de la U, los individuos o grupos deben desprenderse de todo lo que no es importante; así, se abre paso al mejor futuro. Una vez que se experimenta este estadío, el nivel de energía se eleva y se siente la posibilidad del futuro. Esta etapa cobra especial importancia, ya que para iniciar la cuarta, la elaboración de prototipos, se requiere haberse despendido de todo su bagaje (dejar ir) para poder determinar lo que realmente se necesitará (dejar venir) para así proporcionar soluciones prototipadas en tiempo real (Schamer 2007: 11-12):

Así que el prototipo no es la etapa que viene después del análisis. El prototipo forma parte del proceso de sentir y descubrir en el cual nosotros exploramos el futuro a través del hacer en lugar de hacerlo a través de pensar y reflexionar. Este es un punto de tal simpleza, pero yo he descubierto que es justamente allí donde el proceso de innovación de muchas organizaciones se estanca, en el viejo método analítico de "parálisis por análisis" (Schamer 2007: 13).

Este proceso de prototipado (etapa 4) “también conduce a una dinámica y rápida ampliación de la red de agentes de cambio quienes obtienen provecho para su aprendizaje a través del uso de prototipos y quienes se ayudan los unos a los otros con cualquier tipo de reto de innovación con el que ellos se enfrenten" (Schamer 2007: 13). En la etapa 5 debe revisarse lo que se ha aprendido luego de haber desarrollado prototipos y micro cosmos de lo nuevo, lo que funciona y lo que no y decidir cuál de ellos tendrá mayor impacto en el sistema o situación analizada. Para lograr un mejor resultado de esta evaluación, se requiere la participación de otros grupos de interés, instituciones y sectores. Este proceso concluye con un "ecosistema de innovación que conecta iniciativas con prototipos de alto impacto con las instituciones e interesados que puedan llevarlo al siguiente nivel tanto en escala como en proyectos pilotos" (Schamer 2007: 13).

Las cinco etapas de la teoría $U$ pueden aplicarse tanto a grandes proyectos de innovación como a aquellas iniciativas de cambio menores. "Cuando esta es aplicada a proyectos de innovación de larga escala, el proceso U se desarrolla durante periodos más 
largos de tiempo y en diferentes formas. Como consecuencia la composición de los equipos en este tipo de proyectos con frecuencia cambia y se adapta en cierta manera después de cada movimiento" (Schamer 2007: 13).

Schamer complementa estas etapas con siete capacidades de liderazgo que son condiciones que deben darse para que el proceso $U$ y sus momentos puedan funcionar; sin ellas, no podrían llevarse a cabo ya que su recorrido requiere de un trabajo muy duro por parte del equipo, organización o sistema. Estas siete capacidades están incluidas en la nueva tecnología social llamada presencing (Schamer 2007: 14): 1) contener el espacio: escuchar lo que la vida nos pide que hagamos (hacer partícipes a todos; el líder debe sostener un espacio en el que todos se sientan invitados, dejar espacios para que todos contribuyan incluso antes de iniciar un proceso de cambio); 2) observar: prestar atención con la mente totalmente abierta (suspender los juicios personales o pensar en función de experiencias pasadas); 3) sentir: conectarse con el corazón (facilitar procesos de apertura; es decir, tener la mente abierta, el corazón abierto y la intención abierta); 4) presenciar: conectarse con el origen más profundo de su ser y su intención (es un proceso complejo, el corazón abierto permite ver la totalidad y la intención permite actuar desde la totalidad que va emergiendo; es importante conectarse con ambos); 5) cristalizar: acceder al poder de la intención (se crea un impulso que es dirigido por el equipo motor que funciona como un vehículo para que el todo pueda expresarse); 6) hacer prototipos: integrar cabeza, corazón y manos (destaparse y lidiar con la resistencia de pensamientos, emociones e intenciones venciendo la acción reactiva, la reflexión sin acción y hablar sin conectar el origen y la acción); y 7) realizar-actuar: tocar el violín macro (el violín macro hace referencia a situaciones o contextos sistémicos en que se requiere líderes que convoquen a un adecuado equipo de actores, conectados por la misma cadena de valores, y una tecnología social que permita la conjunción de todos los interesados para interactuar desde el debate hacia la creación de lo nuevo) (Schamer 2007: 14-19). Esta lógica se puede apreciar en la siguiente figura:

\section{Figura 9: Una nueva tecnología social con siete capacidades de liderazgo}

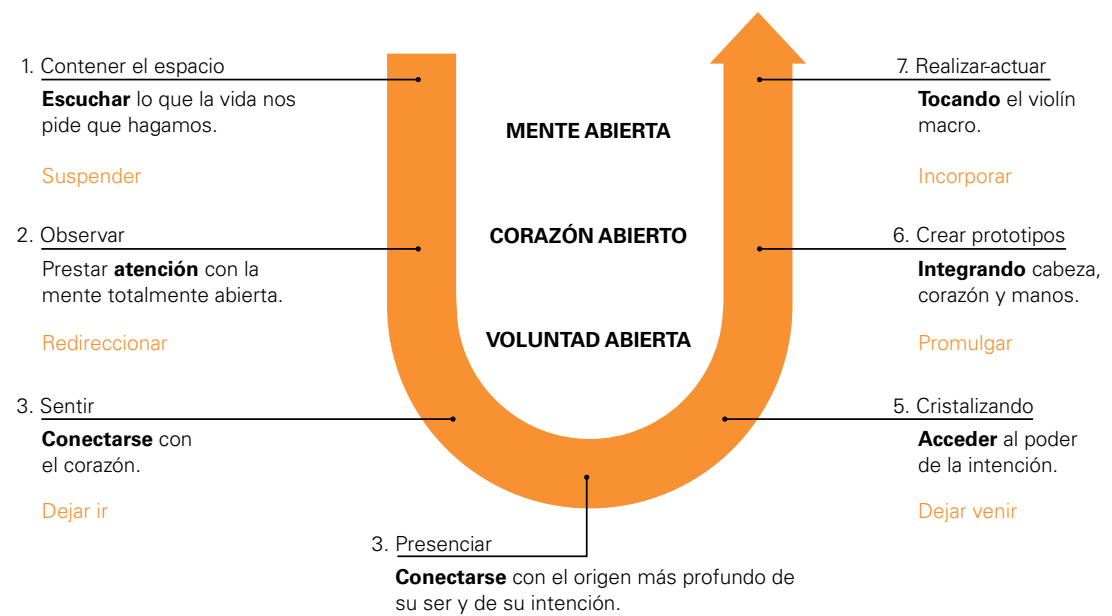

Fuente: Schamer (2007: 18) 
La Teoría U está muy alineada con lo trabajado por Robert Kegan y Lisa Laskow en "Inmunidad al cambio: cómo superarla y desbloquear su potencial y el de su organización"; ambos autores destacan que la mayor parte de personas no cambian ni aunque esté en peligro su vida (comentan el caso de los médicos que les dicen a sus pacientes cardíacos que si no cambian de hábitos morirán e indican que solo uno de cada siete los cambia), por lo que afirman que a veces el deseo o la motivación no son suficientes, lo que fortalece el hecho de que las creencias individuales, además de las mentalidades colectivas de las organizaciones, se combinan para crear una natural y poderosa inmunidad al cambio (2009). Al producirse este fenómeno, es importante que las personas identifiquen estas inmunidades (resistencias) y se desprendan de ellas para que, una vez que se produzca el cambio personal, se pase al organizacional, venciendo la inercia y transformando no solo la vida personal, sino además la laboral (Kegan y Laskow 2009). Podría interpretarse que esta etapa de conciencia y dejar ir las resistencias se ubica en la zona izquierda de la U.

La Teoría U proporciona una visión sistémica a la gestión del cambio, hace énfasis en el proceso de desprendimiento personal que pasa al ámbito social y llega hasta los ecosistemas para la creación de nuevos escenarios. La contribución de esta teoría con el modelo propuesto es crucial dada su relevancia por el potencial impacto que estos aspectos pueden generar en el surgimiento de la teconología social organizacional como motor de innovación y, por lo tanto, de generación de valor.

\subsection{La estrategia del Océano Azul: las cuatro barreras organizacionales}

“La estrategia del Océano Azul es un desafío para que las compañías abandonen el sangriento océano de la competencia y creen espacios seguros en el mercado, en los cuales la competencia no tenga importancia" (Kim y Mauborgne 2005: X). Para lograrlo, la compañía debe aumentar el tamaño de la demanda y dejar atrás la competencia, lo cual implica un cambio, ya que se deberá crear una curva de valor (propuesta de valor) más divergente a un menor costo, lo cual plantea exigencias en la etapa de implementación estratégica (Kim y Mauborgne 2005: 207). Sin embargo, las organizaciones, además del reto del cambio estratégico, suelen presentar barreras organizacionales que no permiten ejecutarlo.La primera es la percepción; es necesario crear conciencia entre los empleados acerca de la necesidad de un cambio estratégico, ya que usualmente las personas están muy cómodas e incluso creen que sus resultados son bastante buenos, entonces la pregunta es ¿para qué cambiar? La segunda barrera es la de los recursos limitados: se supone que mientras el cambio sea mayor, más cuantiosos serán los recursos para ejecutarlo; sin embargo, en la experiencia de los autores de esta estrategia, los recursos disminuyeron en lugar de aumentar. La tercera barrera se relaciona con la motivación: es complicado motivar a los actores clave para que actúen con rapidez y para que sean perseverantes con romper el estado normal de las cosas; este proceso podría ser muy largo. Y la cuarta barrera es la política, "tal como lo manifiesta un gerente, 'en nuestra organización uno recibe el disparo antes de ponerse de pie'" (Kim y Mauborgne 2005: 208). 

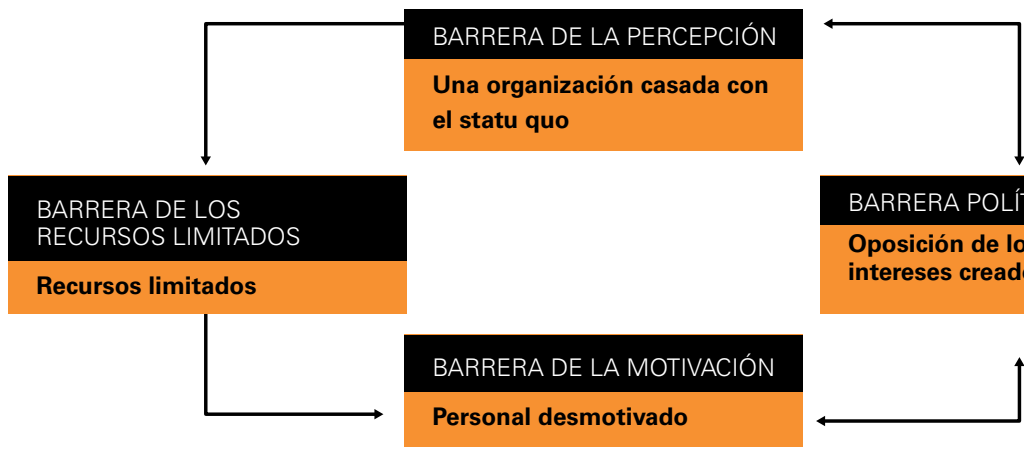

BARRERA POLÍTICA

Oposición de los poderosos intereses creados

Entonces, el gran reto consiste en luchar para vencer estas barreras, mitigar así el riesgo organizacional y lograr que la implantación de la nueva estrategia (del Océano Azul) sea susceptible de ser llevada a la acción. Para esto, Kim y Mauborgne indican que se debe recurrir al "liderazgo para inclinar la balanza, el cual permite superar rápidamente estas cuatro barreras a bajo costo y conseguir al mismo tiempo el respaldo de los empleados para la iniciativa de romper con el estado tradicional de las cosas" (2005: 209). Para conseguir el "liderazgo para inclinar la balanza" es necesaria una palanca fundamental: "los factores de influencia desproporcionada" (Kim y Mauborgne 2005: 212-213).

El liderazgo para inclinar la balanza se apoya en la realidad corporativa rara vez aprovechada de que en todas las organizaciones hay personas, actos y actividades que ejercen una influencia desproporcionada sobre el desempeño. Por consiguiente, contrariamente a lo que se piensa, superar un desafio monumental no es cuestión de montar una respuesta igualmente monumental mediante la cual se mejora el desempeño de acuerdo con las inversiones proporcionales de tiempo y recursos. Al contrario, es cuestión de conservar los recursos, recortar el tiempo y centrar toda la atención en identificar y apalancar los factores que influyen de manera desproporcionada sobre una organización (Kim y Mauborgne 2005: 213).

Es decir, los líderes deberán preguntarse ¿cuáles serán los factores o actos que ejercerán "una influencia desproporcionadamente positiva para romper con el statu quo, para obtener el máximo de cada dólar de recursos, para motivar a los actores clave a fin de que promuevan activamente el cambio y para desmantelar los obstáculos políticos contra los cuales suelen estrellarse hasta las mejores estrategias?" (Kim y Mauborgne 2005: 213). Al concentrarse en estos puntos de influencia desproporcionada, los líderes vencerán las cuatro barreras organizacionales que impiden la implementación de la estrategia del Océano Azul.

"Hacer que las personas vean y experimenten la dura realidad directamente" (Kim y Mauborgne 2005: 215) es una forma de derrumbar la barrera de percepción organizacional, ya que las personas deciden desde su fuero interno el cambio de mentalidad (Kim y Mauborgne 2005: 216) permitiéndoles experimentar "en carne propia los peores problemas operativos" (Kim y Mauborgne 2005: 216) para romper el statu quo; esto incluye a los supe- 
riores de una organización, ellos también deben vivir estas situaciones, e incluye también el escuchar "personalmente a los clientes más descontentos" (Kim y Mauborgne 2005: 219).

Para vencer la barrera de los recursos limitados "los líderes que inclinan la balanza se concentran en multiplicar el valor de los recursos de los cuales disponen" haciendo uso de "las zonas calientes, las zonas frías y la negociación" (Kim y Mauborgne 2005: 221):

Las zonas calientes son aquellas actividades que exigen pocos recursos pero pueden generar grandes ganancias en materia de desempeño. Por otro lado, las zonas frías se refieren a las actividades que exigen grandes recursos pero tienen un impacto menor sobre el desempeño. Por lo general, en todas las organizaciones hay zonas calientes y zonas frías. La negociación se refiere al intercambio de los recursos sobrantes en un área por los recursos sobrantes de otra a fin de llenar los vacíos (Kim y Mauborgne 2005: 221).

En este punto debe reflexionarse respecto a las actividades que consumen la mayor parte de los recursos pero generan un impacto menor sobre el desempeño y qué actividades tienen el impacto más grande sobre este pero carecen de recursos; así, se consigue un mayor valor (Kim y Mauborgne 2005: 222).

Para que la nueva estrategia sea realidad, es necesario que las personas actúen de una manera "sostenida e importante" (Kim y Mauborgne 2005: 228). " [...] Los líderes que inclinan la balanza siguen la trayectoria contraria para lograr la concentración masiva. Centran su atención en tres factores que influyen de manera desproporcionada sobre la motivación de los empleados. Esos tres factores son las personas clave, la gestión transparente y la atomización" (Kim y Mauborgne 2005: 229). Las personas clave son aquellas que tienen un mayor poder de influencia en la organización, los líderes naturales, las personas más respetadas, los persuasivos o aquellos que tienen el poder para bloquear o desbloquear el acceso a los recursos (Kim y Mauborgne 2005: 229). La gestión de estas personas debe ser transparente y se debe resaltar amplia y repetidamente sus actuaciones con inclusión y equidad, por ejemplo en las reuniones de seguimiento, ya que ellos fungen de agentes de cambio y esta práctica suele imitarse en los niveles inferiores (Kim y Mauborgne 2005: 230-233). La atomización hace referencia a cómo se presenta el "desafío estratégico [...] Si la gente no cree en la posibilidad de cumplir con el desafío estratégico, es poco probable que el cambio sea exitoso" (Kim y Mauborgne 2005: 233). Por esto, si el cambio es de gran magnitud, es importante presentarlo de manera fragmentada para que los agentes de los diversos niveles puedan entenderlo y comprometerse con él (Kim y Mauborgne 2005: 234). Respecto a la barrera política, los autores del Océano Azul afirman que:

La política es una realidad ineludible de la vida en las organizaciones públicas y privadas. Aunque una organización haya llegado al punto de inflexión de la ejecución, siempre hay intereses creados muy poderosos que se alzan en contra de los cambios inminentes. [...] Mientras más probable es el cambio, más feroz y encarnizado es el ataque de las personas que ejercen una influencia negativa -tanto interna como externa- porque buscan proteger sus posiciones. Su resistencia 
puede afectar seriamente el proceso de ejecución, hasta descarrilarlo.

A fin de vencer esas fuerzas políticas, los líderes que operan para inclinar la balanza ponen la mira en tres factores que ejercen una influencia desproporcionada: apalancar a los ángeles, silenciar a los demonios y conquistarse a consejeros para las filas de la alta gerencia (Kim y Mauborgne 2005: 235).

Los ángeles son los que se beneficiarán más con el cambio estratégico, los demonios son los que más pierden con él y un consejero es una persona informada, respetada, políticamente sagaz, que conoce las trampas y la información "sobre los partidarios y los opositores" (Kim y Mauborgne 2005: 235). Los autores del Océano Azul indican que, además de incluir personal con altos niveles de destrezas funcionales en el equipo de alta gerencia, se debe incluir también al consejero (Kim y Mauborgne 2005: 236) y resaltar la importancia de identificar a cada uno de estos tres personajes formando una coalición amplia que impedirá a los detractores adquirir fuerza conociendo muy bien todos los ángulos desde los cuales podrían atacar (Kim y Mauborgne 2005: 236-238).

Finalmente, los autores sostienen que para que el cambio se produzca de una manera más efectiva, es recomendable trabajar con los extremos (liderazgo para inclinar la balanza) en lugar de concentrarse en las masas (sabiduría convencional):

\section{Figura 11: La sabiduría convencional comparada con el liderazgo para inclinar la balanza}

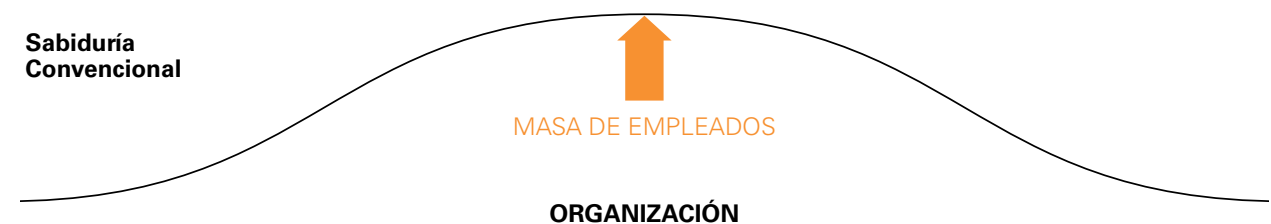

La teoría del cambio organizacional descansa sobre la transformación de las masas. Por consiguiente, los esfuerzos de cambio giran alrededor de la movilización de las masas, lo cual implica uso de recursos enormes y un tiempo prolongado.

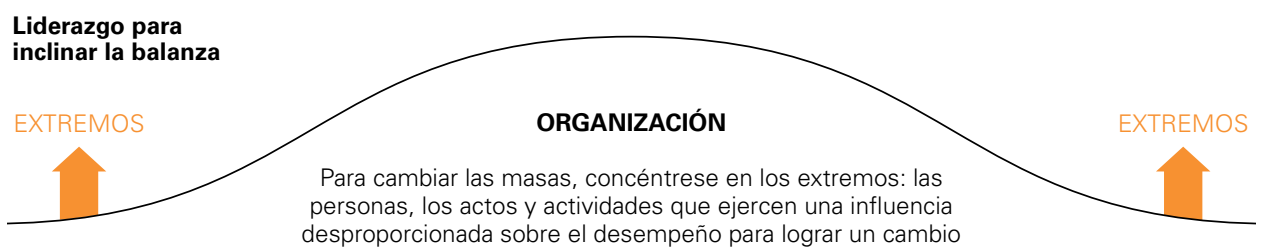
estratégico rápido y de bajo costo.

Las cuatro barreras organizacionales y la forma como sus autores proponen enfrentarlas constituyen un enfoque práctico, concreto y de fácil aplicación en las organizaciones. Es por esta razón que varios de los elementos propuestos podrán apreciarse en la propuesta del modelo de gestión del cambio que se presentará en la siguiente sección del artículo. 
Como ha podido apreciarse, con estos modelos previos, se evidencia que el proceso de gestionar el cambio es complejo y puede ser diverso dependiendo del enfoque que se tome como guía. Enseguida se presenta la propuesta metodológica que recoge varios de los elementos desarrollados en las líneas superiores.

\section{Modelo de gestión del cambio: la propuesta metodológica desde el proceso estratégico}

Para Duck, en la "forma" de gestionar el cambio radica la dificultad (2000: 96); sin embargo, es posible definir una "forma" teniendo en cuenta la revisión bibliográfica previa y la experiencia empírica de la autora como consultora de gestión del cambio. En ese sentido, se plantea el siguiente modelo que consta de ocho pasos, que puede ser seguido con la Figura 13 (Modelo de gestión del cambio desde el proceso estratégico), donde se indica la numeración correspondiente a cada uno.

\subsection{Conformación del equipo de gestión de la transición}

Para empezar, se requiere definir las personas que guiarán el proceso de cambio. ¿Quién será el líder del equipo (Kotter 2000: 13, 15) y con quién contará (personal de apoyo)? Es recomendable que el equipo esté compuesto por facilitadores externos (de una compañía asesora confiable) e internos (especialmente del área de RR.HH.) para tener una mezcla apropiada entre experiencia y técnica y conocimiento de la cultura, respectivamente (Ross y Roberts 2000: 80). A este grupo de líderes Duck lo llama "equipo de gestión de la transición" (2000: 76). Conformado por dos o cinco personas, dependiendo de la envergadura del cambio. Se trata de un equipo temporal: cuando el proceso se estabiliza, el equipo se deshace (Duck 2000: 76).

Las habilidades de comunicación y empatía son muy requeridas para los integrantes de este equipo, así como estar capacitados en la metodología de gestión del cambio y en su rol durante el proceso. Estas personas proveerán apoyo para la selección de los integrantes más idóneos del proyecto de cambio y detectarán a aquellos que pueden asumir el rol de agentes de cambio (promotores del cambio) en la organización y aquellos que podrían ser sus enemigos o resistirse pasiva o activamente al proceso (sujetos de cambio). "Primero debemos distinguir nuestra manera de gestionar el cambio en función de su origen: a. Podemos ser iniciadores del cambio, nosotros lo iniciamos proactivamente. b. Podemos ser descubridores del cambio, el cambio nos llega y somos reactivos." (Fernández 2009: 43). “El agente de cambio debe utilizar su conocimiento de los empleados, y las técnicas de gestión del cambio, para reducir al mínimo los costos de la transición y ayudar a introducir los cambios en las mejores condiciones" (Sang Long y Khairuzzaman Wan Ismail 2012:24).

Duck resalta que este equipo debe "establecer el contexto del cambio y facilitar orientación, [... estimular la conversación, [...] facilitar unos recursos adecuados [...], coordinar y alinear proyectos [...], asegurar la congruencia de los mensajes, las actividades, las políticas y los comportamientos [...], ofrecer oportunidades para la creación conjunta [...], anticipar, identificar y afrontar los problemas del personal [...] y preparar la masa crítica [...]" (2000: 100-104). 
En esta etapa es particularmente importante que los miembros del equipo iniciador apliquen la Teoría U (Schamer 2007) y faciliten este proceso con todas las personas de la organización. Como se ve, en este paso destacan también los roles del líder y del agente del cambio y su aporte como aliados y facilitadores de todo el proceso, siguiendo el aporte del incrementalismo lógico (Quinn y Voyer 1997: 143).

Por otro lado, es importante recalcar que, dependiendo de la magnitud del cambio y del grado de formalización (Claver Cortés y otros 2006: 190) de la organización, será necesario incorporar al proceso de cambio un equipo encargado de elaborar la documentación pertinente referido a la estructura, los procesos, perfiles, manuales de organización y funciones, etc., que se van a ver afectados por el proceso de cambio (ver 1 en la Figura 13).

\subsection{Clarificar el cambio}

El objetivo de este equipo es elaborar el Plan de Gestión del Cambio (definir la visión del cambio, los objetivos, estrategias, etc.). Para la elaboración de este plan, es indispensable hacer un diagnóstico organizacional que permita establecer las estrategias más adecuadas para la organización:

La organización debe estar convencida de la necesidad de cambiar para asegurar el éxito del proceso, pero además debe contar con herramientas que ayuden a los directivos a identificar los factores que limitan la capacidad de cambio e indiquen el sentido o dirección del cambio. [...] una herramienta de diagnóstico que permite identificar, todas las etapas del proceso de cambio, en qué estado se encuentra la organización, cuáles son las variables organizativas que limitan su desempeño y consecuentemente, indica qué hay que cambiar y hacia dónde (Alfonso y otros 2008: 4).

La aplicación de la estrategia del Océano Azul (Kim y Mauborgne 2005: 212) en lo referente a romper con las barreras organizacionales (percepción, recursos limitados, motivación y política) puede ser de gran ayuda en esta etapa. Alfonso y otros señalan que la metodología del diagnóstico debe considerar tres enfoques: "el estratégico, el de servicio y el de proceso a las etapas de la gestión del cambio: planeación, implantación y control o su traducción en los tres circuitos de la plataforma para la gestión el cambio organizacional integrado, la cual se toma como objeto de análisis para el establecimiento y selección de las variables de diagnóstico" (2008: 4). La metodología que plantean los autores incluyen la concepción y objetivo de la metodología de diagnóstico, determinar las preguntas y su agrupación en sistemas, confección de la lista de chequeo, construcción del modelo que relaciona las preguntas de cada sistema y entre los sistemas, aplicación del diagnóstico, análisis de los problemas identificados y definición de estrategias a seguir (Alfonso y otros 2008: 4, figura 2). Se trata de elaborar una herramienta que permita recoger información relevante de la organización. 
De acuerdo a la experiencia de la autora, es particularmente importante en esta etapa conocer cuál es la disposición de la organización para el cambio: por áreas, por equipos de trabajo, por zonas, por oficinas, por edades, por antigüedad, por género, etc. Su grado de motivación para el cambio, su información previa del proceso de cambio y qué conocimientos y actitudes posee que sean relevantes para el proceso. En este punto se define la línea base y la brecha que debe ser cubierta. El proceso de relevamiento de esta información puede hacerse a través de entrevistas personales con un grupo reducido y significativo de trabajadores que luego permita elaborar encuestas, cuyos resultados puedan ser la base para mediciones posteriores y masivas. El resultado de esta etapa de relevamiento y diagnóstico debe llevar a la elaboración del Plan que contenga objetivos y estrategias específicas sobre todo en el campo de la comunicación, motivación, palancas y capacitación. La estrategia de cambio racional o egoísta (Duncan citado en David 2013: 235) apoya esta afirmación empírica, así como los pasos uno y tres de los "Ocho pasos de la gestión del cambio de arriba abajo" propuesta por Kotter (citado en Johnson y otros 2006: 539).

Teniendo claro el diagnóstico, es necesario que todos en la organización tengan claro hacia dónde se dirige con este proceso (Kotter 2000: 16-17), por qué y para qué se va a cambiar, con objetivos específicos, detallados y medibles (Especial Directivos 2012: 6); se debe establecer el sentido de urgencia (Kotter 2000: 9-12) y la dimensión del proceso de cambio (micro o macro cambio), el esfuerzo que se requerirá y su impacto, si lo motivan causas internas o externas (Sandoval 2014: 165), etc.

El diagnóstico también cobra relevancia debido a que parte de las personas piensan que la organización está buscando deshacerse de su personal, achicar la estructura o simplemente no entienden cuál es la razón de tanto esfuerzo. Es importante "poner sobre el tapete" el impacto que el proceso de cambio podría tener en el elemento humano para un adecuado manejo de expectativas, ansiedad, miedo, sensación de estar perdiendo (posición, capacidad, conocimiento), frustración, etc. Evidenciando esta situación, Fernández destaca las etapas de la "curva de descubrimiento" por las que pueden pasar los colaboradores:

a. Enfado: "no puede ser" , "esto es imposible” . b. Rechazo: "así no saldrá bien” ,"no va a funcionar" . c. Nostalgia: "el otro funcionaba mejor" , "todo va a ser diferente" . d. Miedo: "¿cómo será en el futuro?" , "me temo lo peor" . e. Negociación: "¿qué beneficios obtendremos?" , “cómo podemos hacerlo?" f. Decisión: "sí" , "no” , "puedo vivir con ello" . g. Ajustes: "yo personalmente haría..." , "entonces tenemos que hacer... [sic]" . h. Compromiso: "funciona bien" , "a mí [sic] me gusta" (2009: 43-44).

Jaffe y Scott diseñaron un cuestionario que permite establecer en qué etapa de la curva del cambio se encuentra cada integrante de la organización en el que plantean veinticuatro afirmaciones que el evaluado debe responder de acuerdo a cómo se sienta identificado y que da como resultado el estadio en una de las cuatro etapas que se propone en la curva: negación o rechazo, resistencia, exploración y compromiso (2003). Traduciendo su propuesta, la curva de cambio se visualizaría de la siguiente manera: 


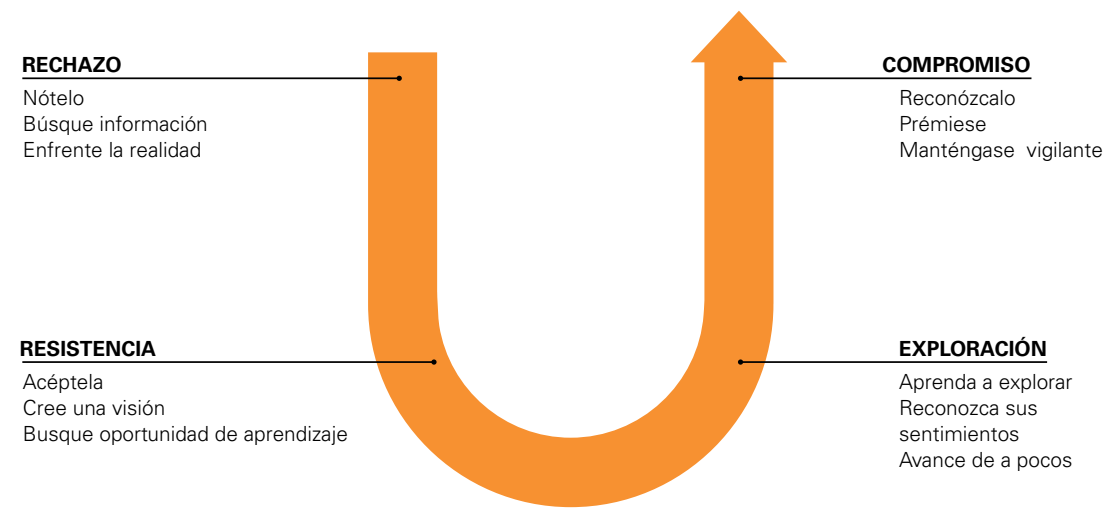

Fuente: Adaptado de Jaffe y Scott (2003: 15).

Los autores explican en qué consiste cada etapa, cuáles son las características de las personas que pasan por cada una y en la figura previa pueden apreciarse algunas recomendaciones para las personas que se encuentren en cada una de ellas (Jaffe y Scott 2003). Como puede verse en esta figura, gráficamente, se evidencia el vínculo entre la Curva del Cambio y la Teoría U (Schamer 2007). En particular, para la mayoría de gestores, resulta interesante conocer las causas que explican la resistencia al cambio (Alonso 2014: 25-26):

- $\quad$ No conocer cuál es el cambio que se plantea ni la visión de a dónde se pretende llegar y cuál es el impacto que todo el proceso tendrá sobre los afectados. Las personas se resistirán a cualquier cambio si no conocen en qué consiste, para qué se realiza y cuál va a ser su impacto tanto a nivel personal como en la organización.

- La percepción que no pueden cambiar, por no saber cómo hacer lo que les corresponde o por sentir que no tienen las habilidades requeridas para la nueva situación. Esta sensación provoca una parálisis involuntaria pero que es percibida como resistencia al cambio.

- No querer cambiar, ya que se considera que no conviene o que obliga a moverse fuera de una zona de confort. Esta falta de motivación puede producirse por el desacuerdo con el motivo del cambio, por la incertidumbre sobre los efectos del nuevo estado, o por la pérdida de identidad generada en el marco de referencia actual.

Como se indicó líneas arriba, la clarificación del cambio, además de incluir el diagnóstico (Johnson y otros 2006: 504-513), incorpora la identificación de la etapa en la que se encuentran las personas que pasarán por un proceso de cambio. La Teoría U (Schamer 2007) puede ser un complemento que ayude en este proceso. Por otro lado, compartir esta información es parte del cambio educativo que plantea David como una de las tipologías más comunes en el que incluye también al estilo forzado y racional (David 2013) como se ha visto en la sección cuatro de este artículo. Estos conocimientos marcan el inicio de la formulación, ya que permitirán precisar las estrategias del plan de gestión del cambio. 


\subsection{Coalición directiva: patrocinadores y red de agentes de cambio}

Como se ha visto en las secciones anteriores, el liderazgo es crucial: todo proceso de cambio debe tener un patrocinador, un líder que acompañe. Una persona que inspire confianza y motive, que guíe discretamente y que influya en el personal. Que sea la cara visible del cambio y esté disponible para escuchar y retroalimentar a las personas que lo requieran, que plantee una visión e integre la formulación e implementación: liderazgo estratégico (Hitt y otros 2015: 371), las siete capacidades de liderazgo de la Teoría U (Schamer 2007: 14). Este punto se vincula con el paso dos planteado por Kotter en su modelo (citado en Johnson y otros 2006: 539).

Este patrocinador (iniciante) debe tener la capacidad de crear una coalición directiva (Kotter 2000: 13, 15) que integre un equipo de patrocinadores apoyadores (sostenedores del proceso) en línea con la estructura jerárquica de la organización. Usualmente el propietario de la empresa o el director de la organización pueden asumir este rol (patrocinador iniciante) apoyado de personal con autoridad de mando formal intermedio como gerentes de división, gerentes funcionales, jefes o supervisores (patrocinadores sostenedores).

Es responsabilidad del equipo de gestión de la transición construir un patrocinio informado y comprometido con el cambio. En ese sentido, desde la perspectiva empírica de la autora, es importante asesorarlos en su rol y responsabilidades en el proceso de cambio. Por su jerarquía, lo más recomendable es visitarlos personalmente y tener una charla breve sobre los aspectos más relevantes del proceso y cómo es útil su apoyo. Una vez que los patrocinadores (iniciante y sostenedores) estén alineados con las estrategias de la gestión del cambio, podrán brindar soporte a los agentes de cambio y persuadir a los sujetos de cambio. Incluso algunos autores afirman que poner en práctica el "coaching ejecutivo en tiempos de cambio en la organización puede tener una amplia gama de efectos positivos" como el logro de metas, centrarse en soluciones, estar mejor preparado para el cambio, disminuir la depresión, entre otros (Grant 2013: 276).

Una vez que la coalición directiva esté conformada y educada, es importante contar con equipos de soporte en los que las personas se vean involucradas a modo de una "estructura en cascada" que siga el orden jerárquico del organigrama. Con esta actividad se atiende el paso cinco del modelo propuesto por Kotter (citado en Johnson y otros 2006: 539). En su cúspide se verá al patrocinador iniciante apoyado de los patrocinadores sostenedores que a su vez se apoyan en los agendes de cambio, quienes brindan soporte a los sujetos de cambio. En cada nivel jerárquico pueden variar la cantidad de patrocinadores, agentes y sujetos. En esta relación se compromete a cada uno de ellos a tomar un rol proactivo en el proceso de cambio y a percibir que este es "suyo". Esta "organización" funciona como una red de agentes de cambio o estructura de soporte paralela que facilita el apoyo en equipo y sostiene los esfuerzos de la transición. Monitorea el proceso, interviene cuando es necesario, reconoce problemas, diseña acciones para facilitar el cambio, retroalimenta y toma decisiones correctivas si es necesario. Esta estructura en cascada debe estar incorporada en el Plan de Gestión del Cambio. Con esta red, se reduce el riesgo identificado por Balogun y Johnson como crítica al modelo de Kotter de arriba abajo (Johnson y otros 2006: 539). 
Tener un líder que funja de patrocinador iniciante (alto directivo), contar con patrocinadores sostenedores (directivos intermedios) y agentes de cambio que se entremezclen en la estructura jerárquica es clave para formar una red que permita que la organización esté alineada y comprometida con el proceso de cambio y que la participación en la formulación, implementación y control sea integradora y bidireccional (de arriba abajo y viceversa). El rol de la red también es susceptible de ser monitoreada y retroalimentada tanto en la formulación como en la implementación o control. Esta lógica incluye también la recomendación de Kim y Mauborgne de utilizar el liderazgo para inclinar la balanza (2005: 239): el cambio se producirá de una manera más efectiva si se trabaja con los extremos. Este punto puede apreciarse en la Figura 13.

\subsection{Palancas de cambio}

El entendimiento del proceso de cambio debe ir desde la cúspide de la estructura hasta el nivel más bajo de la organización y debe ser sistémico para poder identificar todos los elementos que puedan impactarlo y entender la lógica que los mueve. "La tarea consiste en gestionar la dinámica, no los elementos" (Kotter 2000: 75). Para esto es importante reconocer cuáles son las palancas de cambio (Johnson y otros 2006: 521-536) que servirán como facilitadores organizacionales (la comunicación, el trabajo en equipo, el estilo gerencial, por ejemplo), que potencian el proceso, y cuáles serán las barreras potenciales (disposición al cambio, la compensación, la capacitación, por ejemplo), u obstáculos, que deben ser retirados del camino hacia la visión (Kotter 2000: 21-23). Será importante tenerlas claramente identificadas y jerarquizarlas.

El diagnóstico organizacional (Alfonso y otros 2008), la clarificación del cambio a través del análisis de la curva del cambio (Jaffe y Scott 2003), la Teoría U (Schamer 2007) y el enfoque de las cuatro barreras organizacionales (Kim y Mauborgne 2005) pueden permitir la identificación de estas palancas. Estos conceptos deben estar también integrados en el Plan de Gestión del Cambio proponiendo estrategias para capitalizar y minimizar cada grupo respectivamente. Sobre cómo minimizarlas se han desarrollado algunas recomendaciones: establecer discusiones abiertas para reducir el temor y compartir las experiencias de otras organizaciones, resaltar los beneficios del cambio, comunicar lo que se hará y definir recompensas según los puestos de trabajo, entre otros (Especial Directivos 2012).

Las palancas deben monitorearse durante todo el proceso de cambio. Se espera que en la medida en que se vaya avanzando, las barreras hayan decrecido y que los facilitadores se hayan potenciado. En esa medida, se replantearán las estrategias para gestionarlas. Como se ve, el proceso de seguimiento es permanente en todos los pasos planteados y, poco a poco, se deben ver los resultados que van dando forma al proceso de transformación como plantea Kotter en el paso seis de su modelo (citado en Johnson y otros 2006: 539). Este tema se puede ver en el punto 4 de la Figura 13 más abajo.

\subsection{Comunicación}

Desarrollar un Plan de Comunicaciones a la audiencia interna y externa a la organización es crucial (Kotter 2000: 15). Para esto, es particularmente importante el diagnóstico inicial 
realizado en la segunda etapa. A través de un Mapa de Stakeholders se pueden definir las audiencias impactadas por el proceso de cambio, su importancia y los contenidos, medios, estilos y frecuencia de las comunicaciones con cada uno. "El principio conductor es simple: usar todos los canales posibles" (Kotter 2000: 20). Esta actividad es parte del paso cuatro del modelo de gestión del cambio de arriba abajo planteado por Kotter (Johnson y otros 2006: 539). Adicionalmente, "la comunicación debe adaptarse finalmente a las nuevas formas de liderazgo y de gestión. Vamos a necesitar una comunicación más transparente y capaz de conectar con las preferencias y preocupaciones de las personas a través de contenidos más emocionales [...]" (Borrás 2013: 96).

Hay que tener en cuenta también que, con el objetivo de romper con la barrera de los recursos limitados (Kim y Mauborgne 2005: 222) se deben usar los medios de comunicación disponibles en la organización. Como se dijo previamente en la clarificación del cambio, debe plantearse una línea base también respecto a la comunicación para establecer objetivos con indicadores precisos en este tema (impacto, lectoría, conocimiento, etc.). Adicionalmente, se sugiere contemplar un Plan de Crisis ante cualquier situación inesperada que pudiera presentarse (que no funcione el sistema implementado, que los clientes del nuevo territorio no respondan adecuadamente a las estrategias, que la reestructuración del organigrama esté trayendo complicaciones u otro proceso de cambio).

Cada cierto tiempo se deben evaluar y medir todas las estrategias comunicacionales planteadas, por ejemplo, identificar aquellos canales más efectivos, potenciarlos y descartar aquellos que no reporten beneficios. Como se evidencia, esta paso también está contemplado en la formulación; sin embargo, también es susceptible de ser implementado y evaluado (ver 5 en la Figura 13).

\subsection{Motivación}

¿Cómo hacer que el personal se motive? Es difícil, más aún cuando no cree o no confía en el proceso de cambio. Es por eso que los pasos previos deben estar consolidados para que las estrategias de motivación funcionen y generen compromiso, además de entender el fuero interno de todos los participantes del proceso para llegar al desarrollo de esa nueva tecnología social que promueve la Teoría U (Schamer 2007) y así lograr vencer la inmunidad al cambio (Kegan y Laskow 2009). En este punto también cobran particular importancia los tres factores que sugieren trabajar Kim y Mauborgne: personas clave, gestión transparente y la atomización (2005: 229).

El personal confía más cuando conoce lo que pasará, cómo y cuándo (Plan de Comunicación), cuando se conoce y sabe que es capaz de salir airoso del proceso porque posee las actitudes necesarias (autoconocimiento) y cuando sabe que además cumplirá sus propios objetivos de crecimiento personal y profesional (estrategia de cambio racional o egoísta). El Plan de Motivación contemplará entonces estrategias de desarrollo humano e integración del equipo para contribuir con el autoconocimiento personal y grupal, manejo emocional ya que hay que dirigir sentimientos (Duck 2000: 86), eventos de esparcimiento para contribuir con espacios de relajación, fomento de la camaradería (Duck 2000: 89) y reconocimiento de logros durante el proceso de cambio, reforzándolo. Este último punto incluye el paso siete del modelo de Kotter (citado en Johnson y otros 2006: 539). El reco- 
nocimiento de logros de corto plazo es particularmente importante (Kotter 2000: 23-25) sin caer en "cantar victoria" (Kotter 2000: 25-27) antes de tiempo.

Al igual que la comunicación, también se debe medir la motivación en función de la línea base definida inicialmente. Se pueden usar encuestas y definir indicadores que permitan el control periódico. Como puede verse, este paso también está inmerso en las etapas del proceso estratégico: ver 6 en la Figura 13.

\subsection{Capacitación}

Las capacitaciones requeridas en un proceso de cambio podrían ser técnicas (como por ejemplo para el manejo de una nueva herramienta tecnológica) o para facilitar procesos de reflexión que permitan llegar a las etapas cuatro (co-creando) o cinco (co-evolucionando) de la Teoría U (Schamer 2007: 13). Identificar tempranamente las "capacidades necesarias" (Duck 2000: 93) puede traer muchas ventajas. Se disminuyen esfuerzos innecesarios y se concentran las fuerzas en aquellos conocimientos que son relevantes para el proceso de cambio. "Los equipos necesitan disponer de las capacidades y habilidades para descubrir, evaluar y ejecutar las mejores ideas. Si no se invierte el tiempo y dinero en desarrollar esas habilidades constantemente, no se puede esperar un proceso de innovación continua" (Alonso 2014: 26).

Elaborar un plan de capacitación será útil para estimar esfuerzos y tiempos, así como los requerimientos logísticos. La capacitación puede ser interna (recursos humanos propios) y/o externa (empresa especializada), inhouse o outdoor. Se sugiere evaluar los conocimientos adquiridos al final de la capacitación, así como la calidad de esta y la infraestructura utilizada.

Al igual que para los planes de comunicación y motivación, también es importante contar con indicadores precisos que permitan monitorear el proceso de capacitación. Así también, la capacitación debe planificarse (formulación), organizarse y dirigirse (implementación) y controlarse (evaluación): ver 7 en la Figura 13.

\subsection{Evaluación}

El último paso, no necesariamente secuencial, consiste en la evaluación de los indicadores definidos: durante el proceso de cambio, al final del proceso y, de ser necesario, después del proceso también. La evaluación entraña la retroalimentación permanente de todo el modelo y su seguimiento, y, tal como lo sugiere Kotter en el paso ocho de su modelo (citado en Johnson y otros 2006: 539), se requiere el anclaje o institucionalización de los nuevos planteamientos:

La culminación formal del proceso implica que el cambio se ha arraigado en la cultura organizacional (Kotter 2000: 27-28); sin embargo, se debe recordar que:

Durante los últimos años hemos ido experimentado un "momento" de continuo cambio. Un cambio acelerado, promovido por la globalización de los mercados, el incremento de la competencia, las nuevas tecnologías, las exigencias de los clientes y de los empleados, así como por el marco legislativo y político en el que 
nos encontramos. Todo ello ha originado que la empresas [sic] haya experimentado una transformación intensa, precipitada y tremendamente fluctuante (Alonso 2014: 24).

Es decir, el proceso no termina totalmente, la organización debe estar atenta y, es más, debe promover "la necesidad de otorgar autonomía y responsabilidad a los empleados para que puedan ser más creativos, colaborativos y participativos en la creación del futuro de sus organizaciones, movilizándolos hacia la innovación" (Alonso 2014: 24). La innovación debe ser un elemento en la cultura. La visión respecto al cambio es que implica un proceso continuo y las organizaciones deben estar preparadas para asumirlo como tal de una manera creativa. "En medio de este escenario revuelto, muchas son las incógnitas con las que deben hacer frente las organizaciones y que siembran cierta incertidumbre ante el desconocimiento de lo que puede acontecer. Nuevos tiempos requieren nuevas soluciones [...]" (Rodríguez de Galarza 2013).

En este punto, se resaltan la gestión de la innovación y los facilitadores organizacionales que la favorecen (Rueda-Cáceres y Sánchez-Torres 2015: 1), así como haber logrado el desarrollo de las siete capacidades de liderazgo que propone la Teoría U (Schamer 2007: 14-19) para darle sostenibilidad al proceso de innovación permanente.

De acuerdo a la experiencia empírica de la autora, se sugiere culminar el proceso con la elaboración de un informe que incluya los resultados obtenidos, que permita hacer un seguimiento al proceso, que contenga una matriz FODA ${ }^{1}$ del proceso de cambio, que rescate las lecciones aprendidas, y que plantee estrategias y recomendaciones para el sostenimiento del proceso de cambio. Es útil que este documento tenga forma de memoria que pueda servirle a la organización como un manual para futuros procesos de cambio y mejorar el modelo ejecutado.

1. Matriz de Fortalezas, Oportunidades, Debilidades y Amenazas (David 2013: 176-178). 
Figura 13: Modelo de gestión del cambio: desde el proceso estratégico.

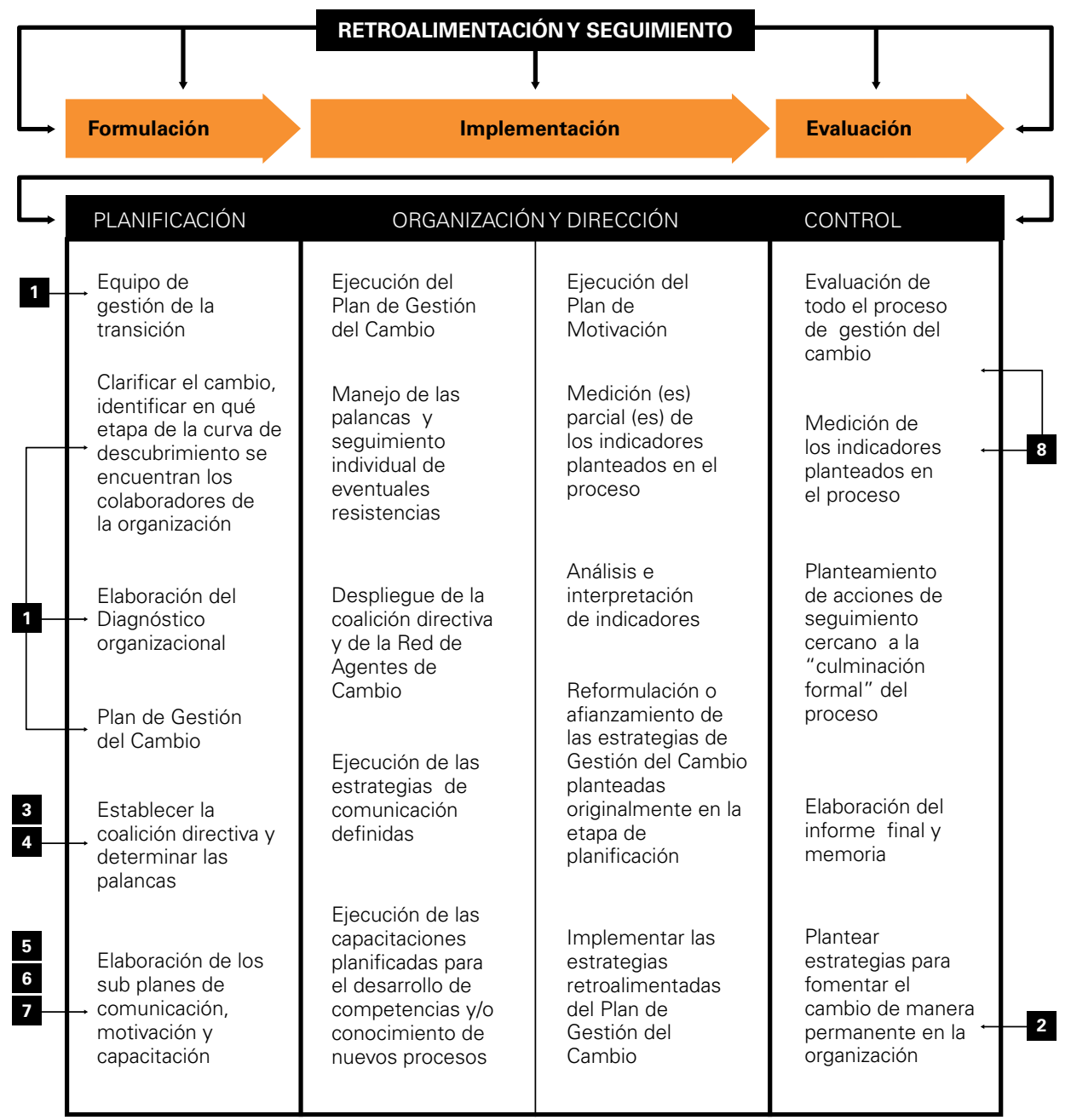

Fuente: Elaboración propia

Cabe resaltar que los pasos propuestos no son necesariamente secuenciales, que su monitoreo debe ser permanente y debe facilitar la retroalimentación continua, que el rol del líder es crucial como unificador del proceso estratégico, capaz de estimular la participación de todas las personas estimulando sus propuestas y capaz de aglutinar los poderes de la organización hacia la visión, con un enfoque de proyectos que permita identificar actividades, responsables, recursos, tiempos, etc., de manera precisa y susceptible de ser controlado, teniendo una perspectiva sistémica y en la búsqueda permanente de la generación de valor.

Como se aprecia en la Figura 13, los ocho pasos están alineados con los elementos del proceso estratégico; sin embargo, es importante que la gestión del cambio sea parte del proceso estratégico de la organización, es decir, que en el proceso de planea- 
miento o formulación organizacional se incluyan los proyectos de innovación y que estos sean apropiadamente gestionados a través de un modelo como el planteado. Nótese en dicha figura que en la etapa de formulación se inician la mayor parte de pasos y luego, en implementación, se ejecutan y se realizan las mediciones parciales que se sugiere sean cada cierto periodo de tiempo para luego pasar a una etapa de evaluación general, luego de haber retroalimentado (reafirmado o corregido) las estrategias para, finalmente, plantear estrategias de seguimiento y dejar las bases para futuros procesos de cambio.

\section{Conclusiones}

Como se ha evidenciado en la revisión de la literatura, la escuela de aprendizaje de Mintzberg (1999) y el incrementalismolLógico de Quinn y Voyer (1997) son enfoques que permiten acercarse a la tipología del cambio y ayudan a mejorar su comprensión; los elementos que describe Johnson y otros (2006: 503) son de mucha utilidad y también se incorporaron en el modelo propuesto, así como la estrategia de cambio planteada por David (2013: 234-235).

Otros modelos relevantes para la propuesta lo constituyen los ocho pasos de la gestión del cambio de arriba abajo de Kotter (citado en Johnson y otros 2006: 539), la gestión del cambio desde los proyectos de Barroso y Delgado (2007), la Teoría U (Schamer 2007) y cómo vencer las barreras organizacionales planteadas en la estrategia del Océano Azul (Kim y Mauborgne 2005) por sus aportes desde diversos puntos de vista que, analizados sistémicamente, suman para el logro del objetivo del presente documento: modelar una metodología de gestión del cambio que sea susceptible de ser implementada, integradora y flexible, desde un enfoque sistémico y de generación de valor organizacional.

El modelo planteado es susceptible de ser aplicado en organizaciones empresariales, públicas y sociales, y tiene como objetivo contribuir a una cultura organizacional que fomente la innovación, en la búsqueda permanente de ventajas competitivas sostenibles y dentro del marco del proceso estratégico. También es importante tener en cuenta el desarrollo de estrategias emergentes y que la gestión del cambio debe contemplar tanto la visión basada en recursos como aquella que contempla las fuerzas externas e institucionales soportadas en el liderazgo estratégico, que anticipe, soporte, faculte y propicie el cambio de manera permanente.

El modelo de gestión del cambio planteado busca crear un ambiente de aceptación al cambio introducido en la organización teniendo en cuenta la perspectiva sistémica y la generación de valor en el contexto del proceso estratégico, enfocado en generar estrategias que permitan el logro de ventajas competitivas en las organizaciones. Con una buena gestión del cambio habrá más posibilidades de comprensión y aceptación de la necesidad de cambiar, de involucrar a las personas en el proceso, de generar un espacio de optimismo frente al reto, de entender lo que pasará, de recibir aportes y de crear un clima de apertura que permita la expresión franca y constructiva de todos los aspectos relacionados al proceso. Y que este sea continuo, en la búsqueda permanente de la innovación, mejora permanente y aprendizaje, de manera individual, grupal y organizacional.

A modo de anexo se presenta un caso de aplicación que pretende mostrar de una forma muy breve que este modelo fue implementado; por tanto, es susceptible de ser replicado en otras organizaciones respetando las particularidades de cada una. He ahí su relevancia. 
Finalmente, este artículo no pretende dar una receta. Como en la cocina, depende de "la mano" del cocinero y cómo este tiene la astucia de adaptarla a sus circunstancias. Así, cada organización puede personalizar la propuesta de acuerdo a sus características particulares.

\section{Anexo \\ Caso de aplicación}

A continuación, se presenta el caso de Olímpica S.A, empresa en la cual se aplicó el modelo de gestión del cambio propuesto en el artículo "Gestión del cambio: una propuesta metodológica desde el proceso estratégico", entre los años 2008 y 2009. Gran parte de la información proporcionada en esta sección del artículo es producto de la experiencia de la autora como líder del equipo ${ }^{2}$ de gestión del cambio del Proyecto Gacela, nombre con el que fue bautizado el proceso de implementación de SAP ${ }^{3}$ (Sistemas, Aplicaciones y Productos en procesamiento de datos) en Olímpica.

Olímpica es una empresa colombiana fundada en 1953 en la ciudad de Barranquilla por Richard Char cuando adquirió el almacén "Olímpico", una pequeña botica ubicada en esa localidad donde se comercializaban abarrotes y artículos de farmacia. Con el paso de los años y al tomar la posta los hijos de don Richard: Fuad, Farid y Simón, se constituyó "Char Hermanos Ltda". En 1968 se inauguró la primera Supertienda Olímpica iniciándose el proceso de cobertura del mercado nacional con las tiendas de Cartagena y Santa Fe de Bogotá (Olímpica S.A. 2010). Años más tarde, en la década de los 80, la empresa continuó su expansión con la inauguración de nuevos puntos de venta en todo el ámbito nacional colombiano. Hoy en día, Olímpica es una de las compañías líderes en la comercialización de productos de consumo masivo a través de una cadena de droguerías, superdroguerías, supertiendas y superalmacenes que en total suman más de 250 establecimientos, destacándose por una estrategia de buen servicio y los mejores precios (Olímpica S.A. 2014).

En el año 2008, Olímpica inició un proceso de cambio tecnológico que incluyó la implementación de SAP en sus siguientes operaciones:

- $\quad$ Retail: Hace referencia a todas las actividades relacionadas con el core business de la empresa; es decir, la comercialización de productos de consumo masivo. Las funcionalidades implementadas fueron: abastecimiento, centro de distribución y logística de tienda, precios y promociones e inteligencia de negocios.

- No Retail: Compras no retail, ventas y distribución, y producción y costos.

- Datos maestros/POS: Datos maestros e interfaces POS (Point of Sale).

- Finanzas/Contabilidad: Cuentas por pagar, tesorería, contabilidad general,

2. La autora participó como líder del equipo de gestión del cambio por el lado de la empresa de consultoría peruana que facilitó el proceso de implementación de SAP.

3. "[...]íder de mercado en software de aplicaciones para empresas. SAP ayuda a las organizaciones a combatir los efectos de la complejidad, generar nuevas oportunidades para la innovación y el crecimiento, y mantenerse a la delantera de la competencia" (SAP s/f). SAP tiene sus oficinas principales es Walldorf, Alemania y su presencia abarca más de 130 países y 282000 clientes en todo el (SAP s/f) 
controlling, activo fijo y localizaciones, cuentas por cobrar, análisis de rentabilidad e integración financiera.

Adicionalmente, se contó con un "Frente Técnico" que incluyó el Desarrollo ABAP (ABAP: es un lenguaje de programación de SAP) y BASIS (componente técnico de SAP); la Gestión del Cambio que atendía dos asuntos: Humano y Procesos; Interventoría, conformada por una empresa externa tercera encargada de vigilar de manera objetiva la correcta implementación del proyecto; Normalización de Datos, para la estandarización de la información que sería luego incorporada a SAP; y los Sistemas Legacy (legados).

La estructura organizacional del Proyecto puede verse en la figura a continuación.

\section{Figura 14: Estructura Organizacional del Proyecto Gacela}

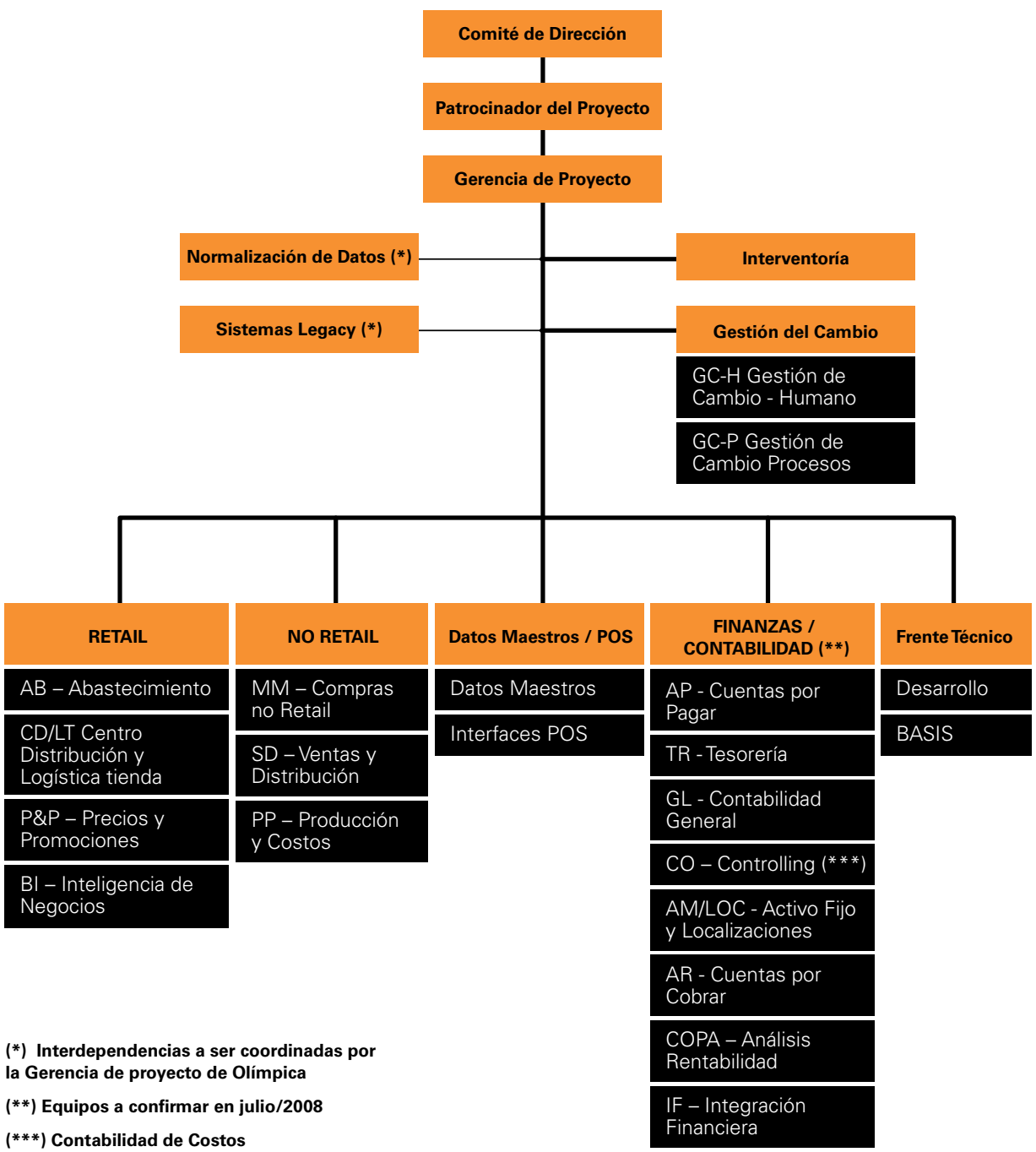


Como puede apreciarse, el Proyecto Gacela fue de gran envergadura. Participaron más de 20 consultores por parte de la empresa facilitadora y más de 70 trabajadores de Olímpica S.A. durante aproximadamente un año (Proyecto Gacela 2008).

\section{Modelo de gestión del cambio aplicado:}

1. El equipo de gestión de cambio se fue designado por la gerencia del Proyecto Gacela e inició sus labores con el lanzamiento oficial del mismo y con la conformación del equipo gestor de la transición. Todas sus actividades fueron gestionadas a través de un enfoque de proyectos en la que se plantearon actividades, recursos, fechas, avances y reuniones de seguimiento regulares. La empresa Olímpica seleccionó al personal que participaría durante un año en él y la empresa facilitadora también determinó el suyo. El frente de gestión del cambio estuvo compuesto por la autora del presente artículo (consultora de gestión del cambio de la empresa facilitadora) y su par fue la gerente nacional de gestión humana de Olímpica, con el apoyo de dos a cinco personas en diferentes etapas de la implementación, dependiendo de la demanda de actividades de cada etapa.

2. Clarificación del cambio: Este equipo inició su trabajo en el mes de febrero de 2008 con entrevistas a profundidad personales que incluyeron inicialmente preguntas abiertas y otras cerradas y de opciones múltiples (en una escala de Likert del 1 al 5). Se entrevistaron a 27 personas que integraron el Proyecto y una muestra de 17 personas de la empresa que no estaban asignadas a este (8 personas de primera línea, 7 jefes y 2 ejecutivos). El objetivo de estas entrevistas fue la realización de un diagnóstico inicial o punto de partida que permita el establecimiento de las estrategias de gestión del cambio. Los hallazgos pueden resumirse en lo siguiente: cultura organizacional orientada hacia la flexibilidad, la innovación y la obtención de resultados, coherencia estratégica, expectativas favorables al proceso de cambio, niveles de compromiso y comunicación organizacional favorables, y, como oportunidades de mejora, el trabajo en equipo, el sistema de información y la formalización oportuna de procesos. A partir de esta información, se identificaron las creencias que tenía el personal de Olímpica y su disposición frente al proceso. Las razones del cambio fueron estructuradas a partir de los antecedentes que se recopilaron de la compañía: necesidad de mayor y mejor disposición de la información del negocio, mayor velocidad, oportunidad y confianza de la información, entre otros.

3. Por otro lado, se preparó la coalición directiva que estaba compuesta por personal clave y que tenía como objetivo hacer evidente una presencia más cercana de la alta dirección de Olímpica y de sus gerentes con el personal del Proyecto. Se recomendó un estilo de liderazgo inspirador, que genere confianza, protección, exposición, orientación, manejo proactivo y positivo de conflictos y adecuada gestión de la disciplina. También se reforzó la necesidad transmitir y de mantener una estrecha coordinación y comunicación con el Proyecto para, así, proporcionar una imagen de unidad y compromiso. Por otro lado, también se hizo énfasis en el compromiso con la formalización de los procesos que serán impactados por la implementación de SAP y su comunicación, así como en el hecho de que también se involucre a las personas que no han 
sido asignadas al Proyecto para que enriquezcan la implementación. Las herramientas usadas en este ámbito fueron: visitas de la alta dirección de Olímpica (familia Char) a las oficinas del Proyecto con mensaje motivador, la presencia y disposición del patrocinador del Proyecto permanentemente, reuniones informativas y de estímulo con el equipo del Proyecto, la formalización de los procesos de la organización, así como la elaboración del manual de funciones, la determinación de la nueva estructura organizacional producto del cambio y reuniones individuales con personal clave para corregir situaciones anómalas y mitigar posibles riesgos.

4. Las palancas del cambio también fueron identificadas: la comunicación era la fortaleza más importante de Olímpica, seguida del manejo de la gente, las capacitaciones, la disposición al cambio de conducta, las actividades de integración, el estilo gerencial, la administración de recursos humanos y la compensación, beneficios y premios. Una barrera identificada fue el trabajo en equipo, por lo que se priorizaron diversas actividades para revertirla.

La etapa de formulación concluyó con la elaboración de los planes de comunicación, capacitación y motivación:

5. Plan de comunicación: tenía como objetivo intensificar los mecanismos de comunicación del Proyecto Gacela teniendo en cuenta cuatro públicos objetivo: ejecutivos y jefes, personal de primera línea, personal asignado al Proyecto y personal no asignado al Proyecto. El mensaje en todos los medios se centró en resaltar los siguientes puntos: el costo de mantener la situación actual, los objetivos que buscaba el Proyecto, la metodología de trabajo, los logros parciales, manejo de las expectativas, alcance de la implementación de SAP, los beneficios de la implementación para Olímpica (para las unidades, gerencias y puestos individuales de trabajo). Los medios de comunicación usados fueron: los voceros (para el personal de primera línea), quienes recibieron capacitaciones respecto al mensaje para que pudieran transmitir esa información; los mensajes emergentes en las computadoras y las carteleras informativas (para todos los públicos), las presentaciones informativas ad hoc (para los ejecutivos y jefes), el Boletín Gacela y la Olimpinet (recursos físicos y electrónicos para todos los públicos), y las reuniones grupales y cartelera informativa para el personal asignado al Proyecto.

6. Plan de Capacitación: se priorizó esta actividad con el objetivo de reforzar la preparación de la organización para el cambio. En particular, se debían identificar tempranamente las necesidades de capacitaciones "técnicas", es decir, las referidas al uso de SAP. De esta forma, se planificaron con anticipación las capacitaciones SAP y se adicionaron capacitaciones en temas de desarrollo humano, como el manejo del tiempo, manejo de conflictos, manejo del estrés, gestión por competencias, impacto humano del cambio, trabajo en equipo, entre otros, los cuales buscaron plantear reflexiones personales que permitieran la ruptura individual y colectiva de paradigmas "freno" del proceso de cambio y abrir la mente hacia un nuevo futuro individual y organizacional.

7. Plan de motivación: su objetivo era el reforzamiento e incremento del nivel de motivación al interior del equipo del Proyecto. Por otro lado, también se consideró importante el fortalecer e incentivar el trabajo en equipo, así como la promoción de eventos de 
integración y esparcimiento que refuercen la unidad. Las actividades asociadas a este plan fueron la determinación de premios simbólicos para logros parciales, eventos de esparcimiento (almuerzos, bowling, cenas, fiestas, celebraciones de cumpleaños, entre otros) y eventos de integración trabajados a partir de outdoor team building.

8. Cada plan definió sus respectivos indicadores que se medirían regularmente con el objetivo de monitorear y evaluar su efectividad y retroalimentar constantemente las estrategias.

Cabe precisar que durante el Proyecto se identificaron algunas personas que requirieron sesiones de coaching como apoyo para la comprensión del proceso y la generación del compromiso para reforzar las estrategias planificadas con un mayor nivel de personalización.

En la siguiente figura puede apreciarse la evolución de las mediciones realizadas a tra-vés de encuestas en dos periodos durante el proceso de implementación de SAP en Olímpica:

Figura 15: Foco de evaluación de la gestión del cambio en el Proyecto Gacela

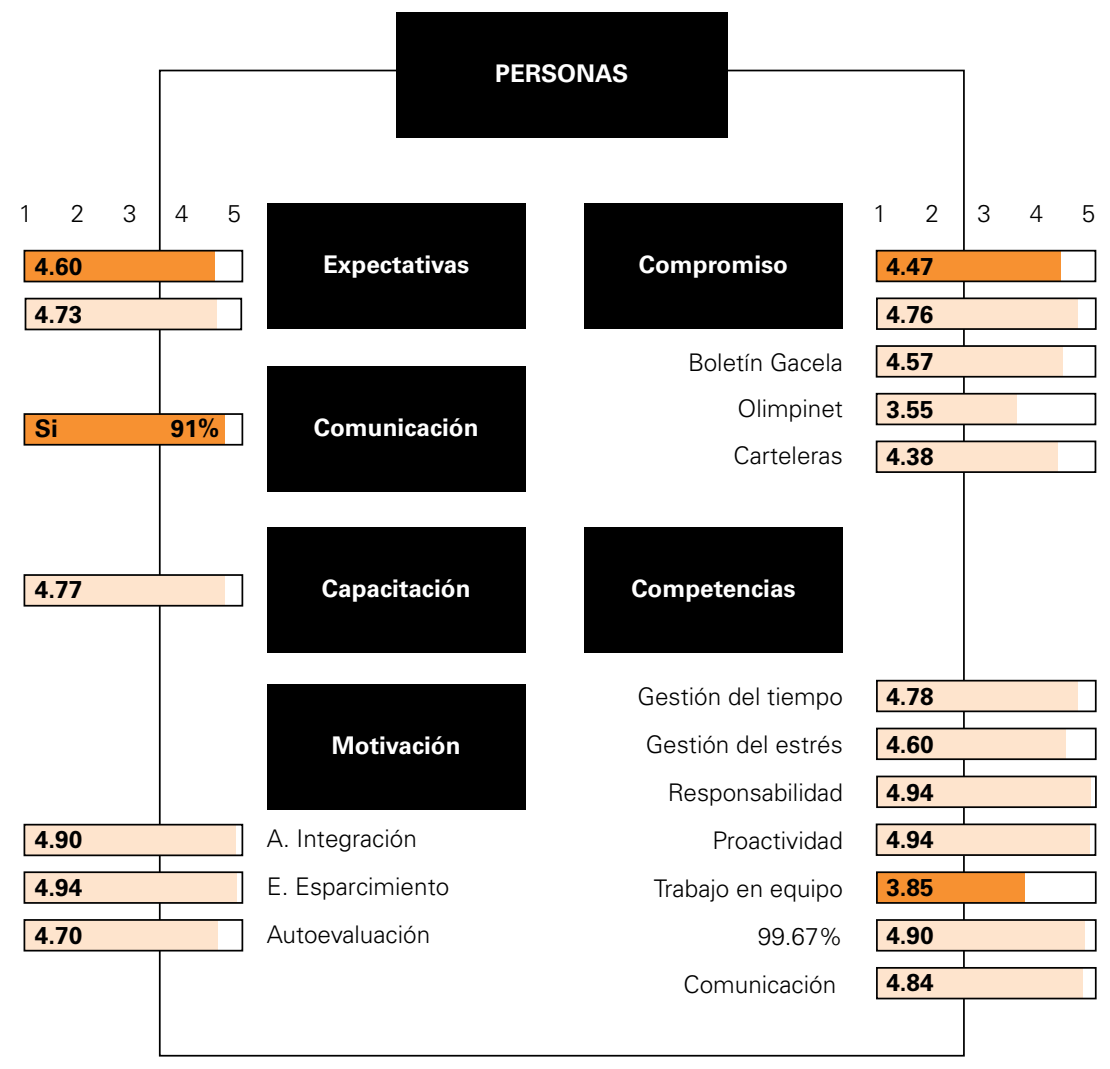

Fuente: Elaboración propia

El Proyecto Gacela se ejecutó en el tiempo previsto y con los recursos previstos. Los resultados de la gestión del cambio aplicados siguiendo el modelo propuesto fueron positivos y la organización la considera como un caso de éxito. A inicios del año 2009 se 
concluyó con el Proyecto y el área de gestión humana de Olímpica, que capitalizó el conocimiento de la gestión del cambio aplicada y aprendió a gestionar el proceso, lo replicó a nivel nacional con éxito, ya sin el apoyo de una empresa de consultoría.

Particularmente durante este proceso, se rescatan la confianza expresada en el equipo directivo de Olímpica (comité de dirección, patrocinador y gerencia del proyecto), en el equipo de consultoría (que aportó con su experiencia en este tipo de procesos de cambio), y en el equipo humano de la empresa responsable del Proyecto, así como la construcción de un clima positivo, enriquecedor, de apertura y ayuda mutua como facilitadores de procesos de reflexión y crecimiento personal, grupal y organizacional. El enfoque de proyectos también fue fundamental para la medición de los avances y su respectivo control, así como el monitoreo de logros parciales y totales.

Durante la implementación del Proyecto Gacela se evidenciaron diferentes elementos del marco teórico revisado en el artículo "Gestión del cambio: una propuesta metodológica desde el proceso estratégico": el enfoque sistémico, la generación de valor, la estrategia de cambio educativo y racional, el incrementalismo lógico, el modelo de los ocho pasos de la gestión del cambio de arriba abajo, la gestión de cambio desde la gestión de proyectos, la Teoría U y cómo enfrentar las cuatro barreras organizacionales, entre otros. 


\section{Aiken, Carolyn y Scott Keller}

2009

"The Irrational Side of Change Manage-

ment." McKinsey Quarterly, número 2, pp.

100-109. Consulta: 17 de agosto de 2015.

http://web.b.ebscohost.com/ehost/detail/

detail? sid $=89 \mathrm{a}$

\section{Alfonso, Daniel y Otros}

2008

“Diagnóstico para el proceso de cambio integrado". Ingeniería Industrial. La Habana, volumen XXIX, número 1, pp.3-7.

\section{Alonso, Aurora}

2014 "Gestión del cambio motor de innovación" Capital Humano. Madrid, número286, pp. 24-26.

\section{Ashkenas, Ron}

2013 "Change Management Needs to Change". Harvard Business Review. Consulta: 15 de julio de 2015

https://hbr.org/2013/04/change-manage-

ment-needs-to-cha/

\section{Barroso, Gloria y Mercedes}

Delgado

“Gestión del cambio organizacional a través de proyectos". Ingeniería Industrial. La Habana, volumen XXVIII, número 1, pp. $42-46$

\section{Blázquez Manzano, Alberto}

2013 “Un modelo de pensamiento estratégico para favorecer la gestión del cambio en las organizaciones". AD-minister. Medellín, número 23, pp. 9-24.

\section{Borrás, Helena}

"Changemanagement: las personas, el centro de la estrategia de negocio". Capital Humano. Madrid, número 279, pp. 92-96.
Claver Cortés, E., E.M. Pertusa Ortega y J.f. Molina Azorín

2006

"Caracterización de las estructuras mecánica y orgánica a partir de las principales dimensiones estructurales". Investigaciones Europeas de Dirección y Economía de la Empresa, volumen 12, número 2, pp. 187-204.

\section{Daft, Richard}

Teoría y diseño organizacional. Décima edición. México D.F.: Cengage Learning.

\section{D’alessio Ipinza, Fernando}

2013

El proceso estratégico. Un enfoque de gerencia. Segunda edición. México D.F.: Pearson Educación.

\section{David, Fred}

2013

Conceptos de administración estratégica. Décimo cuarta edición. México D.F.: Pearson Educación.

\section{Duck, Jeanie}

"Gestionar el cambio". En ATHOS, Anthony y otros. Harvard Business Review: gestión del cambio. Barcelona: Ediciones Deusto, pp. 73-104.

\section{Especial Directivos}

2012

"Pautas para mejorar la gestión del cambio organizativo". Especial Directivos. Madrid, número 1601, pp. 5-6.

\section{Fernández, Javier}

2009 


\section{bibliografía}

\author{
Ferrazzi, Keith \\ 2014 \\ "Managing Change, One Day at a Time". \\ Harvard Business Review, Boston, número \\ julio-agosto, pp. 23-25.
}

\section{Gettler, León}

2015

"Changing Change Management." Acuity.

Sidney, número 9, p. 48.

\section{Gitman, Lawrence}

2003

Principios de Administración Financiera.

Décima edición. México D.F.: Pearson

Eduación

\section{Grant, Anthony}

"The Efficacy of Executive Coaching in

Times of Organisational Change". Journal of

Change Management. Londres, volumen

14, número 2, pp.258-280.

\section{Hamel, Gary}

“Innovación estratégica y creación de valor". Harvard Deusto Business Review, número 156, pp. 18-26.

\section{Hart, Stuart}

"A Natural-Resource-Based View of the

Firm". The Academy of Management Review, volumen 20, número 4, pp. 986-1014.

\section{Hill, Charles, Gareth Jones y Melissa Schilling}

Administración estratégica: teoría y casos.

Un enfoque integral. Onceava edición.

México D.F.: Cengage Learning.

\section{Hitt, Michael, Duane Ireland y}

\section{Robert Hoskisson}

Administración estratégica. Competitividad

y globalización: conceptos y casos. Onceava edición. México D.F.: Cengage Learning.
Jaffe, Dennis y Cynthia Scott

2003

"Mastering the Change Curve". Training Location, pp. 1-15. Consulta: 16 de agosto de 2015.

http://www.traininglocation.com/mastering-change-curve-assessment-paper.pdf

\section{Johnson, Gerry, Kevan Scholes} y Richard Whittington

Dirección estratégica. Séptima edición. Madrid: Pearson Educación.

\section{Kegan, Robert y Lisa Laskow}

Immunity to Change: How to Overcome It and Unlock the Potential in Yourself and Your Organization. Harvard Business Press. Consulta: 9 de noviembre de 2015.

https://hbr.org/product/immunity-to-changehow-to-overcome-it-and-unlock-t/an/1736HBK-ENG

\section{Kim, W. y R. Mauborgne}

2005 La estrategia del océano azul. Bogotá: Norma.

\section{Kotter, John}

2000

"Liderar el cambio." En ATHOS, Anthony y otros. Harvard Business Review: gestión del cambio. Barcelona: Ediciones Deusto, pp. 7-29.

\section{Lloréns Montes, F.J., A.J. Verdú} Jover y V.J. García Morales

\section{"Flexibilidad estratégica en entornos hip-} ercompetitivos: una visión basada en los recursos financieros de la empresa". Revista Española de Financiación y Contabilidad, volumen XXXV, número 129, pp. 387-410. 


\section{bibliografía}

\section{Mintzberg, Henry}

1999

Safari a la estrategia. Una visita guiada

por la jungla del management estratégico.

Buenos Aires: Granica.

\section{Mintzberg, Henry, James}

Quinn y John Voyer

El proceso estratégico. Conceptos, contextos y casos (edición breve). México D.F.:

Prentice Hall Hispanoamericana.

\section{Olímpica S.A.}

Olímpica.com. Consulta: 9 de noviembre de 2015. http://www.olimpica.com

\section{Olímpica S.A.}

2010

Sitio Oficial Olímpica S.A. [página de Facebook]. Consulta: 9 de noviembre de 2015. https://www.facebook.com/SupertiendaOlimpica/info/?tab=page info

\section{Peng, Mike W.}

Estrategia global. México D.F.: Cengage Learning.

\section{Peteraf, Margaret A.}

"The Cornerstone of Competitive Advantage: A Resource-Based View". Strategic Management Journal, volumen 14, número 4, pp. 179-191.

\section{Porter, Michael}

Michael Porter - ¿Qué es estrategia? [videograbación]. Consulta: 13 de agosto de 2015

https://www.youtube.com/watch?v=Knwk15020J4

\section{Porter, Michael}

Ventaja competitiva. Creación y sostenibilidad de un rendimiento superior. Madrid: Pirámide.

\section{Porter, Michael}

\section{Porter Michael y Mark Kramer}

2011

"Creating shared value." Harvard Business Review. Boston, número enero-febrero, pp. 1-17

\section{Proyecto Gacela}

2008

Información generada en el proyecto Gacela. Olímpica S.A., Barranquilla.

\section{Quinn, James y John Voyer}

"El incrementalismo lógico: cómo manejar la formación de estrategias". En MINTZBERG, Henry, James QUINN y John VOYER. El proceso estratégico. Conceptos, contextos y casos. México D.F.: Prentice Hall, pp. 139-145.

\section{Robbins, Stephen y David Decenzo}

Fundamentos de Administración: conceptos esenciales y aplicaciones. México D.F. Pearson Educación.

\section{Rodríguez de Galarza, Nekane}

"Impulsando el Cambio". Capital Humano. Barcelona, número 276, pp. 12-13.

\section{Ross, Rick y Charlotte Roberts}

2000

"Perros que ladran y perros que no ladran". En SENGE, Peter y otros. La Danza Del Cambio. Los retos de sostener el impulso en organizaciones abiertas al aprendizaje. Bogotá: Norma, pp. 78-81.

\section{Rueda-Cáceres, I. y J. Sán- chez-Torres}

“Características para la medición de los facilitadores de gestión como componentes de la capacidad de innovación". ALTEC 2015 Brasil - XVI Congreso Latin-Iberoamericano de Gestión Tecnológica. 


\section{bibliografía}

\section{Sandoval, José Luis}

2014

"Los procesos de cambio organizacional y la generación de valor." Estudios Gerenciales, número 30, pp. 162-171.

\section{Sang Long, Choi y Wan Khai-} ruzzaman Wan Ismail

2012 "The HR Specialist as an Agent of Change". Human Resource Management International Digest, volumen 20, número 2, pp. 24-28.

\section{SAP}

$s / f$

SAP. Consulta: 10 de noviembre de 2015.

http://go.sap.com/latinamerica/about.html

\section{Schamer, Otto}

2007 Otto Schamer. Consulta: 10 de noviembre de 2015 .

http://www.presencing.com/sites/default/ files/page-files/TU-ExecSum-Spanish.pdf

\section{Senge, Peterz}

La quinta disciplina. Buenos Aires: Granica.

\section{Society for Human Resource} Management

"Change Management: The HR Strategic Imperative as a Business Parther." HR Magazine, 1-9.

\section{Strebel , Paul}

2000

“¿Por qué los empleados se resisten al cambio?" En ATHOS, Anthony y otros. Harvard Business Review: gestión del cambio. Barcelona: Ediciones Deusto, pp. 175-197.

\section{Taylor, Joe y Monica Morgan}

2014

"Why Change Management Should Be a Top Priority". MWord, número de agosto, pp. 29-31.

Tushman, M.,W. Newman y E. Romanelli

“Convergencia y transtorno: administración del inconstante paso de la evolución organizacional". En Mintzberg, Henry, James Quinn y John Voyer. El proceso estratégico. Conceptos, contextos y casos. México D.F.: Prentice Hall, pp. 418-426.

\section{Wernerfelt, Birger}

\section{"A Resource-Based View of the Firm".}

Strategic Management Journal, volumen 5, número 2, pp. 171-180.

\section{Fecha de recepción: 17/08/15 Fecha de aceptación: 13/10/15}

